\title{
Salmonids, Stream Temperatures, and Solar Loading- Modeling the Shade Provided to the Klamath River by Vegetation and Geomorphology
}

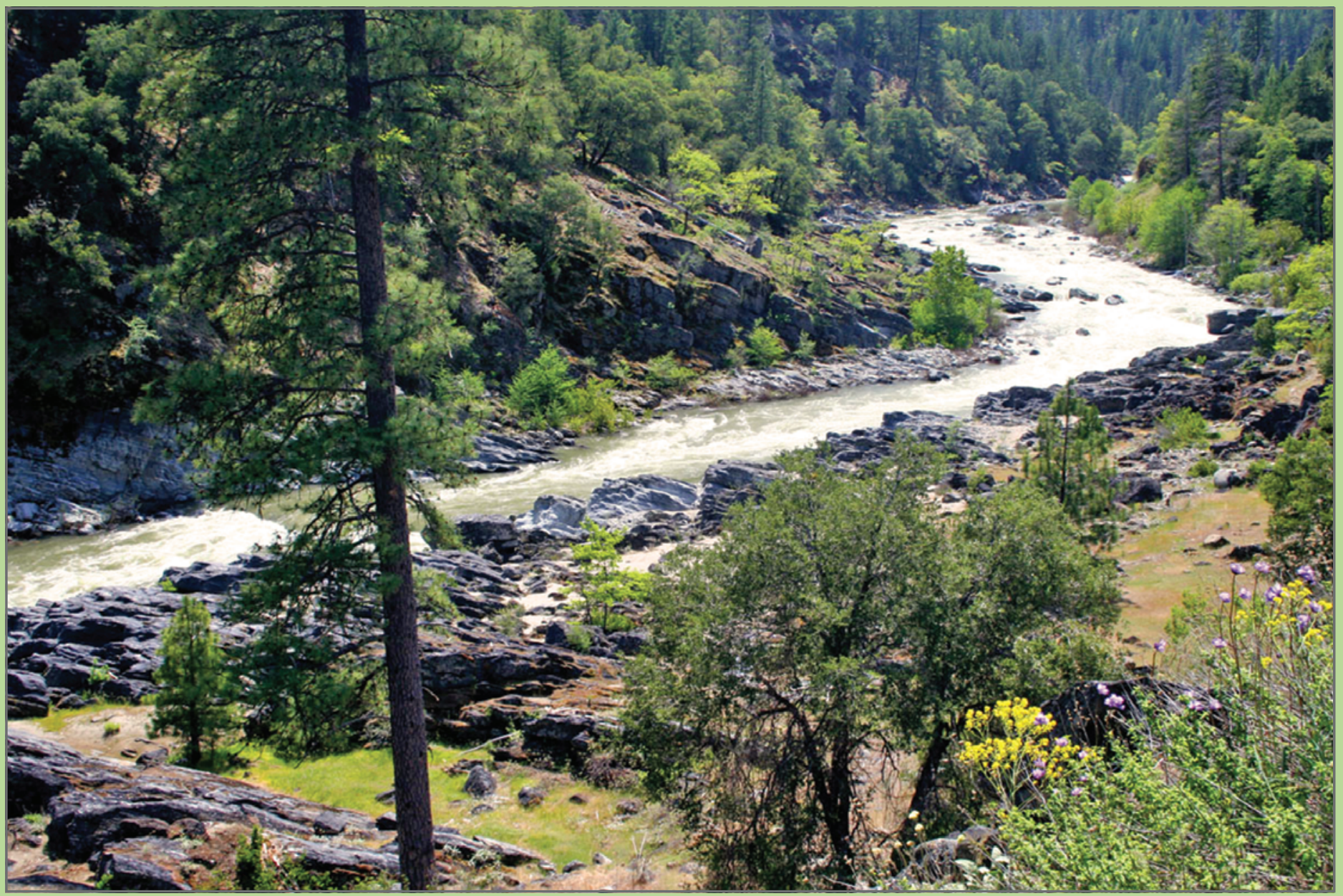

Scientific Investigations Report 2013-5022 


\section{Salmonids, Stream Temperatures, and Solar Loading-Modeling the Shade Provided to the Klamath River by Vegetation and Geomorphology}

By William M. Forney, Christopher E. Soulard, and C. Christopher Chickadel

Scientific Investigations Report 2013-5022 


\section{U.S. Department of the Interior \\ KEN SALAZAR, Secretary}

U.S. Geological Survey
Suzette M. Kimball, Acting Director

U.S. Geological Survey, Reston, Virginia: 2013

For product and ordering information: World Wide Web: http://www.usgs.gov/pubprod Telephone: 1-888-ASK-USGS

For more information on the USGS — the Federal source for science about the Earth, its natural and living resources, natural hazards, and the environment: World Wide Web: http://www.usgs.gov

Telephone: 1-888-ASK-USGS

Any use of trade, firm, or product names is for descriptive purposes only and does not imply endorsement by the U.S. Government.

Although this report is in the public domain, permission must be secured from the individual copyright owners to reproduce any copyrighted material contained within this report.

Suggested citation:

Forney, W.M., Soulard, C.E., and Chickadel, C.C., 2013, Salmonids, stream temperatures, and solar loadingmodeling the shade provided to the Klamath River by vegetation and geomorphology: U.S. Geological Survey Scientific Investigations Report 2013-5022, 25 p. 


\section{Contents}

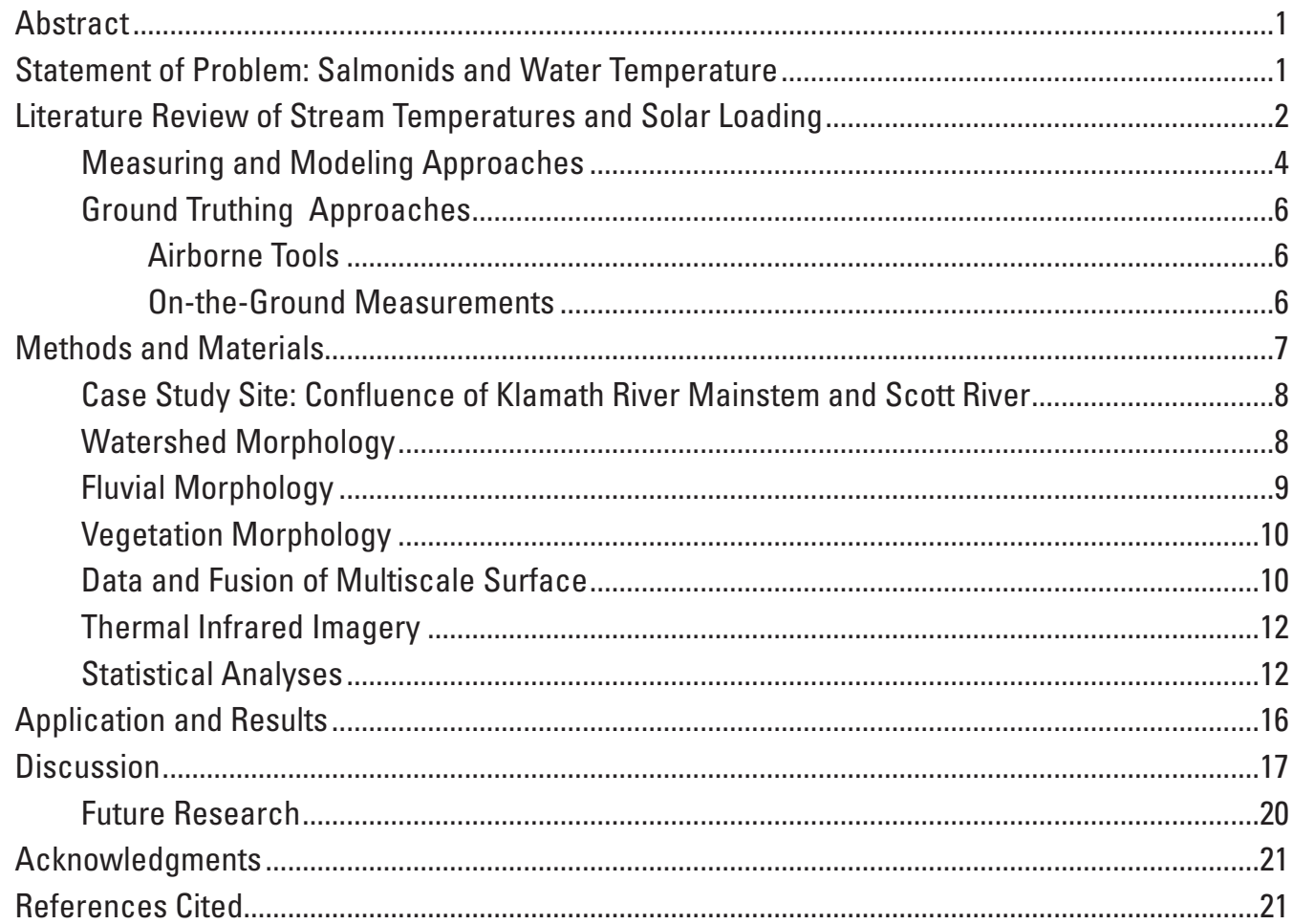

\section{Figures}

1. Figure showing hemispherical coordinate system used in the solar loading model...............6

2. Conceptual schematic showing method development and model application ........................7

3. Map showing the study site and model input extent ..................................................................8

4. Plot showing hydrograph of discharge and gage height on the Klamath River at Seiad Valley, more than 4 kilometers downstream of the study area ............................. 8

5. Photographs of fluvial-channel geomorphic features relevant to shade provision such as incised river beds, cut banks, and steep embankments.......................................

6. Photographs of vegetation morphology and contexts relevant to shade provision ..............11

7. Vegetation canopy morphology derived from airborne LiDAR and shown at an oblique angle at the confluence of the Scott and Klamath Rivers ...........................12

8. Map of solar loading and Solar Model 1 output for the Scott River confluence with the Klamath River

9. Map of solar loading and Solar Model 2 output for the Scott River confluence with the Klamath River.....

10. Graphic showing the calibrated river-surface temperatures via airborne thermal infrared imaging at the Scott River confluence with the Klamath River.

11. Scatterplot of thermal infrared imagery against three differently processed solar loading models

12. Quantile-quantile plots for three solar loading models at the Scott-Klamath River confluence 


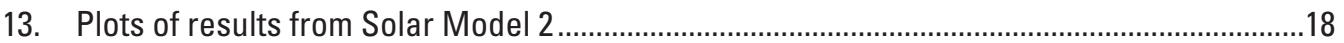

14. Plots of results from Solar Model 3 ………………..........................................................

15. Plot showing cross-correlograms of thermal imagery related to the three differently processed solar models for the Scott-Klamath River confluence......

\section{Tables}

1. Spatial datasets used in the manuscript

2. Nonparametric correlation tests between 3 differently processed solar loading models and thermal infrared data for the Scott-Klamath River confluence.

3. Tests of differences between correlation coefficients of the 3 differently processed solar loading models for the Scott-Klamath River confluence.

\section{Abbreviations}

\begin{tabular}{cl}
\hline CBEM & Channel bare earth model \\
DBH & Diameter at breast height \\
DEM & Digital elevation model \\
DEQ & Oregon Department of Environmental Quality \\
DWR & California Department of Water Resources \\
EAARL & Experimental Advanced Airborne Research LiDAR \\
FEMA & Federal Emergency Management Agency \\
FLIR & Forward looking infrared \\
GIS & Geographic Information Systems \\
GPS & Global Positioning System \\
IR & Infrared \\
LAS & File format for LiDAR data \\
LiDAR & Light detection and ranging \\
MODIS & Moderate Resolution Imaging Spectroradiometer \\
NCRWOCB & North Coast Regional Water Quality Control Board \\
NRC & National Research Council \\
PAR & Photosynthetically available radiation \\
REMS & River and ecosystems models and science initiative \\
TESLA & Tool for explanatory landscape scenario analyses \\
TIR & Thermal infrared \\
TMDL & Total maximum daily load \\
USBR & U.S. Bureau of Reclamation \\
USGS & U.S. Geological Survey \\
VCS & Vegetation canopy structure \\
VDDT & Vegetation dynamics development tool \\
\hline
\end{tabular}




\title{
Salmonids, Stream Temperatures, and Solar Loading- Modeling the Shade Provided to the Klamath River by Vegetation and Geomorphology
}

\author{
By William M. Forney', Christopher E. Soulard', and C. Christopher Chickadel ${ }^{2}$
}

\begin{abstract}
The U.S. Geological Survey is studying approaches to characterize the thermal regulation of water and the dynamics of cold water refugia. High temperatures have physiological impacts on anadromous fish species. Factors affecting the presence, variability, and quality of thermal refugia are known, such as riverine and watershed processes, hyporheic flows, deep pools and bathymetric factors, thermal stratification of reservoirs, and other broader climatic considerations. This research develops a conceptual model and methodological techniques to quantify the change in solar insolation load to the Klamath River caused by riparian and floodplain vegetation, the morphology of the river, and the orientation and topographic characteristics of its watersheds. Using multiple scales of input data from digital elevation models and airborne light detection and ranging (LiDAR) derivatives, different analysis methods yielded three different model results. These models are correlated with thermal infrared imagery for ground-truth information at the focal confluence with the Scott River. Results from nonparametric correlation tests, geostatistical cross-covariograms, and crosscorrelograms indicate that statistical relationships between the insolation models and the thermal infrared imagery exist and are significant. Furthermore, the use of geostatistics provides insights to the spatial structure of the relationships that would not be apparent otherwise. To incorporate a more complete representation of the temperature dynamics in the river system, other variables including the factors mentioned above, and their influence on solar loading, are discussed. With similar datasets, these methods could be applied to any river in the United States - especially those listed as temperature impaired under Section 303(d) of the Clean Water Act—or international riverine systems. Considering the importance of thermal refugia for aquatic species, these methods can help investigate opportunities for riparian restoration, identify problematic reaches unlikely to provide good habitat, and simulate changes to solar loading estimates from alternative landscape configurations.
\end{abstract}

${ }^{1}$ U.S. Geological Survey, Western Geographic Science Center

${ }^{2}$ University of Washington, Applied Physics Laboratory

\section{Statement of Problem: Salmonids and Water Temperature}

Depending on acclimation over their life stages, some salmonids, such as Chinook salmon (Oncorhynchus tshawytscha) and steelhead (O. mykiss), have been shown to have different mortality thresholds (Myrick and Cech, 2004). Hanson (1991) showed that the incipient upper lethal temperature of O. tshawytscha saw a 2.7-fold increase in resistance time to $25^{\circ} \mathrm{C}$ when acclimation temperatures were raised from 12 to $18^{\circ} \mathrm{C}$. Although this makes it difficult to determine a particular temperature threshold above which salmonids cannot survivesome definitive studies of Chinook salmon have suggested 24-25 ${ }^{\circ} \mathrm{C}$ (Brett,1952; Brett and others, 1982) - and increased water temperatures are often confounded with other factors that influence fish growth (such as ration size and quality, disease, dissolved oxygen and other water-quality parameters), the relationship generally holds that salmonids suffer from a higher degree of stress and detrimental effects to physiology and behavior at higher temperatures (Myrick and Cech, 2004).

High water temperatures and stress have been shown to have deleterious physiological impacts on the stenothermal (in other words, capable of living or surviving only in a narrow range of temperature) anadromous fish species Chinook salmon and steelhead, and their performance during particular life stages (Brett, 1971; Everson, 1973; Iverson, 1972; McCullough, 1999; Myrick and Cech, 2004; Wurtsbaugh and Davis, 1977). Sutton and others (2007) suggested that the mainstem of the Klamath River below Iron Gate Dam is a difficult environment for juvenile coho salmon (O. kisutch), Chinook, and steelhead due to decreased flows and increased water temperatures, which can exceed $25^{\circ} \mathrm{C}$ during summer periods. Locations of thermal refugia in the mainstem are typically associated with cool water accretions from tributaries, springs, seeps, groundwater and (or) hyporheic flow (Hatch and others, 2006; Gilbert and others, 1997), from which salmonids have been observed to forage for food (Belchik, 2003; Sutton and others, 2007). This research focuses on the dynamics of maintaining cool water through shading in the mainstem and tributaries that enter the lower Klamath River below Iron Gate Dam.

In 2003, the National Research Council (NRC) published a report identifying the causes of decline and the strategies for 
recovery of endangered and threatened fishes in the Klamath River Basin. In that study, riparian vegetation was noted to have an influence on water temperature, particularly in the lower Klamath Basin and its tributaries below Iron Gate Dam. For example, it noted that the Scott, Shasta, and Trinity Rivers' riparian vegetation has suffered due to land uses such as mining, grazing, and agricultural practices, and the impacts to vegetation pose a threat to salmonid habitat. This threat includes increased bank erosion, reduction in local woody debris, sedimentation of pools, reduction in channel complexity, degradation of water quality, and the loss of shading and canopy cover. Loss in shading contributes to an increase in water temperatures (Abbott, 2002). Given the fact that the Shasta River has been cited as the most important spawning nursery for Chinook (California Department of Water Resources, 2001) as well as being 303(d) listed as water temperature impaired ${ }^{3}$ by the North Coast Regional Water Quality Control Board (2006; NCRWQCB), the threat to salmonids due to loss of shading is greater in the Shasta than the Scott River. The Shasta River also has greater spring-fed base flows while the Scott River suffers from seasonal low-flow habitat limitations (National Research Council, 2003). Furthermore, even though the Salmon River is relatively pristine due to extensive Federal land ownership, the loss of tributary riparian shading, its orientation, and aspect contribute to higher summer river temperatures in the Salmon River watershed (Kier Associates, 1998), which brings into question the influence of watershed and channel morphology on the thermal loading to the river system.

The central question of this effort is: what roles do vegetation and geomorphology have on regulating water temperatures? The focus of this research is the development of an improved method to incorporate the following three postulates:

1. on a vegetation scale, riparian canopy can provide shade. Primary seasonal changes will be a result of deciduous vegetation that provide the majority of shading after it has leafed out during the summer and evergreen conifers that provide shade throughout the year;

2. on a geomorphic channel scale, steep banks can provide local pockets of shading; and

3. on a regional and watershed scale, the orientation of the ridgelines and canyon walls with respect to the azimuth of the sun is a driver of shading.

\section{Literature Review of Stream Temperatures and Solar Loading}

Water temperature regulates the biological activity of aquatic organisms; higher temperatures increase metabolic rates, while at the same time decrease the solubility of dissolved oxygen available to the organisms. Consequently,

\footnotetext{
${ }^{3}$ The Scott River, Salmon River, and mainstem of the Klamath River from Iron Gate Dam to the Pacific Ocean are also listed as water temperature impaired (North Coast Regional Water Quality Control Board, 2006).
}

a stream's peak temperature in the summer is often a critical characteristic of habitat quality for aquatic species such as fish (Beschta, 1997). Davies-Colley and Rutherford (2005) stated that incoming short wave radiation controls thermal regimes of streams (as well as their primary productivity); Moore and others (2005) suggested that in forestry-influenced systems, shading is the dominant control on stream warming; and Flint and Flint (2008) determined that solar radiation is satistically correlated with maximum stream temperature.

To gain further understanding of fluvial thermal dynamics, a simple equation of a stream's temperature prediction is (Brown, 1972):

$$
\Delta T=\frac{N H \times S A}{Q} \times C=\frac{N H \times L}{D \times V} \times C,
$$

where:

$\Delta \mathrm{T}=$ change in maximum daily stream temperature, in degrees Celsius $\left({ }^{\circ} \mathrm{C}\right)$

$N H=$ net heat exchange per unit of surface area, in watts per square meter $\left(\mathrm{W} / \mathrm{m}^{2}\right)$

$S A=$ surface area of stream for a specific reach, in square meters $\left(\mathrm{m}^{2}\right)$

$Q=$ streamflow or discharge, in cubic meters per second $\left(\mathrm{m}^{3} / \mathrm{s}\right)$

$L=$ stream length, in meters $(\mathrm{m})$

$D=$ stream depth (m)

$V=$ stream velocity, in meters per second $(\mathrm{m} / \mathrm{s})$

$C=$ coefficient to convert heat load to change in temperature

This equation shows the relationship of temperature, surface area, flow, length, depth, and velocity, and implicitly includes the variety of heat sources and transfer mechanisms that can factor into $\mathrm{NH}$, which can include solar and longwave radiation, evaporative heat transfer, conduction, and advection (Beschta, 1997). These factors interact as a parcel of water moves downstream and change significantly over the course of a season or during a particular day. Furthermore, Brown's equation suggests that stream-temperature sensitivity to energy inputs ought to decrease as discharge increases (supported by Flint and Flint, 2008; Moore and others, 2005) and that wide, shallow streams will heat up faster than narrow, deep ones, which is supported by the finding of the inverse relationship of stream temperature to depth by Sullivan and Adams (1990). Groundwater accretions (including lateral and pool-bottom seeps) and hyporheic flows that include heat exchanges with geologic substrates along a stream course can confound a simplistic consideration of heat transfer mechanisms (Bohle, 1994). Making the thermal dynamics even more complex, other drivers of stream temperature are drainage position, distance from headwaters, orientation, aspect, channel morphology (Pluhowski, 1972; Webb and Zhang, 1997), precipitation, cloud cover, adiabatic winds, and valley shape and ridgelines (Barton and others, 1985; Sullivan and Adams, 1990; Bohle, 1994; Larson and Larson, 
1996; Rutherford and others, 1997; Moore and others, 2005). Also, there are microclimate factors such as air temperature, humidity, intermittent fog, and wind speed that in turn affect evaporation, conduction, diurnal air temperature, ground temperature, and water temperature (Flint and Flint, 2008; Moore and others 2005; Rutherford and others, 1997). Finally, the relatively high specific heat capacity of water $(4.18 \mathrm{~J} /$ $\left(\mathrm{g}^{\circ} \mathrm{C}\right)$ at $25^{\circ} \mathrm{C}$ ), which acts as a buffer against change (both increasing and decreasing) in temperature (Larson and Larson, 1996), influences stream temperature dynamics. Many of the factors above can be characterized by the generalized form of the following equation of thermal processes related to the dynamics of stream temperature (Moore and others, 2005; modified from Polehn and Kinsel, 2000):

$$
\frac{d T_{w}}{d x}=\frac{\Sigma N H_{a}}{\rho C_{p} v D}+\frac{Q_{g w}}{Q}\left(T_{g w}-T_{w}\right)+\frac{Q_{h y p}}{Q}\left(T_{h y p}-T_{w}\right)
$$

where:

$d T_{w} / d x=$ rate of temperature exchange $\left({ }^{\circ} \mathrm{C}\right)$ of water parcel with distance $x(\mathrm{~m})$ as it flows downstream

$\Sigma N H_{a}=$ net heat exchange by radiation, turbulent exchange, and conduction across the 1) water surface and 2) the sediments of the streambed $\left(\mathrm{W} / \mathrm{m}^{2}\right)$

$Q=$ streamflow $\left(\mathrm{m}^{3} / \mathrm{s}\right)$

$Q_{g w}=$ groundwater inflow rate, in cubic meters per second per meter $\left(\mathrm{m}^{3} / \mathrm{s} / \mathrm{m}\right)$

$Q_{\text {hyp }}=$ hyporheic exchange rate $\left(\mathrm{m}^{3} / \mathrm{s} / \mathrm{m}\right)$

$T_{g w}=$ groundwater temperature $\left({ }^{\circ} \mathrm{C}\right)$

$T_{\text {hyp }}=$ hyporheic water temperature $\left({ }^{\circ} \mathrm{C}\right)$

$T_{w}=$ parcel water temperature $\left({ }^{\circ} \mathrm{C}\right)$

$\rho=$ water density, in kilograms per cubic meter $\left(\mathrm{kg} / \mathrm{m}^{3}\right)$

$C_{p}=$ specific heat of water, in joules per kilogram per degree Celsius $\mathrm{J} /\left(\mathrm{kg}^{\circ} \mathrm{C}\right)$

$v=$ local mean velocity $(\mathrm{m} / \mathrm{s})$

$D=$ local mean depth (m)

The term of greatest interest for this report is $\Sigma \mathrm{NH}_{a}$, but given the context and setting of a particular study, the other parameters that influence temperature regimes cannot be entirely dismissed. $T_{g w}$ has been assumed to be reasonably well-represented by the local mean annual air temperature (Beschta and others, 1987), but gage measurements at depth in the water column indicate greater variability at fine spatial and temporal scales (Jenny Curtis and Mary Ann Madej, written commun. and unpub. data, 2012). $Q_{g w}$ can be an essential driver of stream temperature, particularly over longer time scales and when considering the flow dynamics of a river system with dams or groundwater pumping (Risley and others, 2010). An ambient air temperature station has been used as a proxy for microclimate variables, but use of such devices can introduce error (Rutherford and others, 1997). This generalized form of thermal stream temperature process dynamics has been applied in various forms, with various simplifying assumptions (Allen and others, 2007; Moore and others, 2005). In this case, the heat flux of particular interest is that portion of $\mathrm{NH}_{a}$ attributed to radiation.

Solar radiation reaching a stream is the most important energy source for changing stream temperatures during the daytime periods (Beschta, 1997). Its intensity depends on factors such as the elevation (zenith angle) and orientation (azimuth) of the sun - both of which relate to time of day, latitude, and time of year (Larson and Larson, 1996) - and cloud cover (Theurer and others, 1984). For solar elevation angles of 30 degrees or greater that shine directly on the watercourse, more than 90 percent of the solar radiation penetrates the water surface (Moore and others, 2005).

Shading from woody riparian vegetation has been noted as being effective in decreasing radiation intensity and varies given the length, width, and height of the wooded area. Furthermore, riparian vegetation has been shown to reduce temperature fluctuations and extremes (Lyons and others, 2000). As evidence of the role that riparian vegetation can have in reducing the radiative load to streams, Beschta (1997) cited that field measurements of load reduction in northeastern Oregon could be as much as 80 percent; Lowney (2000) estimated 80 to 90 percent, which would then translate to a reduction in stream temperatures (eq. 2). Equilibrium temperatures calculated from equation 2 (Polehn and Kinsel, 2000) have been found to be higher in unshaded reaches than shaded ones (whether by vegetation, fluvial or watershed geomorphology) during summer afternoons (Bartholow, 2000; Bogan and others, 2003). The removal of vegetation near low-order streams is known to increase summer daily maximum temperatures (Brown and Krygier, 1970; Rishel and others, 1982; Holtby and others, 1988), and the magnitude of summer diurnal fluctuations (Brown and Krygier, 1970). To minimize the thermal impacts of forestry and riparian management, the conventional management approach is to retain forested buffer strips along stream courses (Young, 2000); however, this practice is less frequent on low-order streams (Moore and others, 2005). Furthermore, tree height and distance from a given stream has been found to be a meaningful indicator of the degree of shade (Thomas and others, 1993). It has been shown that low, brushy vegetation can be less effective at moderating water temperature changes in a stream's water column than taller, bushier trees (Hewlett and Fortson, 1982; Macdonald and others, 2003). Finally, lack of adequate mensuration and characterization of the variability in riparian vegetation shading (for example, cottonwoods versus willows versus mixed conifer canopy) has been known to decrease the accuracy of the predictions of in-stream water temperature models (Rutherford and others, 1997; Larson and Larson, 1996).

In terms of defining shade, $S$, as the opposite of exposure, the following relationship can be used to characterize it (Davies-Colley and Rutherford, 2005): 


$$
S=1-\left(I_{i}-I_{0}\right)
$$

where:

$I_{i}=$ irradiance or its time-integral that reaches a given site $I_{0}=$ incident light received at a reference, open site.

Additional factors to consider in this relationship are the temporal and spatial variation of $I_{i}$ and $I_{0}$, the spectral character of the light that filters through the vegetative canopy, and the angular orientation of shading objects (for example, vegetation, channel morphology, watershed characteristics and ridgeline orientation, Welles and Norman, 1991). DaviesColley and Rutherford (2005) propose a measure of diffuse noninterception ${ }^{4}$ as providing a good estimate of long-term, average lighting along stream reaches, which may not be appropriate for application in the Klamath as it has limitations related to assuming the regular occurrence of instantaneous lighting under clear sun conditions.

The physics of shade light is important to consider, especially in terms of shade light's electromagnetic spectrum and how radiation is absorbed by land surface materials. Visible light, also known as photosynthetically available radiation (PAR) in the range of about 380 to $760 \mathrm{~nm}$, contains the most important range for photosynthesis. Since water is transparent to visible solar radiation for short transmission lengths, this differs from the range of the spectrum responsible only for solar heating, which includes visible light and infrared (IR, which is roughly in the range of 0.7 to $30 \mu \mathrm{m}$ ). Furthermore, depending on crown heights, density and configuration of foliage (Black and others, 1991; Federer, 1971; Reifsnyder and Lull, 1965; Vézina and Petch, 1964), vegetation can transmit IR through the canopy to the surface below, while it attenuates the PAR (Moore and others, 2005). PAR transmission through the canopy varies significantly in both space and time, and it is closely related to the canopy gap fraction (Hopkinson and Chasmer, 2007). Consequently, a measurement of only visible light will underestimate total radiation exposure in relation to overall heating by solar radiation (Rutherford and others, 1999). Finally, riparian vegetation, hillsides and streambanks surrounding a particular stream reach emit longwave radiation, which influence water temperatures. The longwave radiation phenomena are typically characterized by the Stefan-Boltzman equation, and can be approximated using ambient air temperatures (Beschta and Weatheredd, 1984; Theurer and others, 1984). The longwave IR imaging portion of the electromagnetic spectrum $(7-14 \mu \mathrm{m})$ is often the emission range detected by forward-looking infrared (FLIR) remote sensing platforms such as those used in this study.

\footnotetext{
${ }^{4}$ The proportion of incident lighting received at a given point on the earth's surface under a sky of uniform brightness.
}

\section{Measuring and Modeling Approaches}

The scientific literature has recognized the need to improve measuring and modeling of the shading to stream courses and the impact shading can have on stream temperatures (Moore and others, 2005; Davies-Colley and Rutherford, 2005). In modeling shade, Davies-Colley and Rutherford (2005) use simplified geometries of "canyons" and "cylinders" where the former is infinitely long, straight, walls of uniform height, and constant setback distance from stream centerline; the latter is a constantly walled height wrapped around a point to emulate a circular pool. Given the complexities such as sinuosity, channel and canyon height variability, and variable solar loading across a given longitudinal profile, neither geometric assumption is satisfying. Furthermore, along previously unshaded streams, they stated the need for models to be able to account for the trajectory of shade recovery as riparian species grow and the canopy develops. For measuring shade, Davies-Colley and Rutherford (2005) stated the need in riparian management for "simple, yet quantitative, methods for measuring shade that are rapid and do not require expensive instrumentation or much offsite computation, and that can characterize light exposure of a stream reach rather than merely a few points."

In an effort to develop a record of stream temperatures with limited or no stream temperature data at certain tributary pour points for a large basin, Flint and Flint (2008) stated the need for more rigorous development of solar radiation parameters that incorporate other site-specific factors beyond topographic shading and cloudiness. Although their stepwise regression modeling suits the needs for their study, some limitations of the Flint and Flint (2008) efforts were that it (1) was conducted at a 30-m digital elevation model (DEM) resolution, (2) did not explicitly include the influence of riparian vegetation nor its extensive variability, (3) was regionally calibrated with 33 solar radiation gages for cloudiness all over the West (from Boise, Idaho, to Tucson, Arizona, to Lubbock, Texas) with the closest gage in Arcata, California, and (4) had both positive and negative coefficients for the independent variable solar radiation as related to the dependent variable maximum stream temperature, which is indicative of the limitation that the model was purely empirically derived. Furthermore, weather stations are often biased to locations in heavily populated areas at low and mid elevations, and are generally lacking in remote upper elevation areas (Rich and $\mathrm{Fu}, 2000$ ).

Focusing on point, dam, and nonpoint sources of temperature dynamics for the possibility of establishing a heat-trading program to meet total maximum daily load (TMDL) requirements, Rounds (2007) built on the work of others using a model called CE-QUAL-W2 on the Willamette River to incorporate shading algorithms and parameters such as topographic and vegetative shading (including length of shadow, topographic angles, treetop elevations, distance to vegetation), latitude, longitude, time of day, and water body orientation into a detailed, spatially-variable representation of 
the energy budget for a given water body. His work included using the modeling tool to characterize riparian vegetation restoration by varying three model inputs: treetop elevation, distance from a river's center to vegetation, and fraction of solar radiation intercepted. Using data from the Oregon Department of Environmental Quality (DEQ), vegetation characteristics were derived from aerial photographs and GIS techniques, and the "system potential" vegetation was an expected, mature structure assumed to occur for particular soils and surface geology with some limited consideration of variable dynamics such as fire disturbance. The "system potential" approach could be improved upon by adopting an approach similar to the vegetation dynamics development tool (VDDT) and the tool for explanatory landscape scenario analyses (TESLA) that include processes and agents of change such as fire, insects, weather, growth and competition within landscape-level vegetation dynamics (ESSA Technologies, Ltd., http://essa.com). Results indicated that riparian restoration efforts in particular locations and of adequate size could help to mitigate differences in the 7-day moving averages of daily maximum water-temperature differences (Rounds, 2007).

To support work on a temperature TMDL on the South Fork of the Eel River, Allen and others (2007) developed a model called BasinTemp that was a mechanistically based model for large basins, rapid deployment, limited input data, and accurate representation and scenario generation of riparian shading effects. Its purpose was "a physically based, largearea assessment model... which complements rather than competes with existing fully mechanistic physically based models. Temperature predictions generated by BasinTemp may be used to guide physically based model applications where more detailed information about the individual mechanisms responsible for stream heating... is required." Although its orientation is not aligned with the site-specific, reach-based, distributed physical-process modeling of this paper, it is important to consider it in terms of an alternate approach. Furthermore, their conclusion is that the essential component of summertime stream heating is solar insolation (direct, diffuse, and reflected), which is congruent with the focus of this paper. Simplifying assumptions of their model include: 1-D steady-state and fully mixed water columns in the horizontal and vertical positions (which negates the potential inclusion of diurnal and maximum/lethal temperatures and presence/ absence of cold water refugia), dismissal of shortwave radiation attenuated through the vegetation canopy (which negates the significance of PAR), and air-water and water-streambed heat exchanges are irrelevant (which simplifies the heat energy processes). Given the limitations of these assumptions, they do use, however, the composite DEM and vegetation elevation raster surfaces in a similar fashion as employed in this research.

Although the Oregon DEQ uses a combination of screening, simulation, and distributed process-based models for their TMDL assessments, a distributed modeling approach allows site-specific data to be incorporated. The distributed, physical-process-based modeling approach includes the network model HeatSource (Boyd, 1996) that the Oregon DEQ uses for temperature impairment determinations. HeatSource relies on multiple data sources such as forwardlooking infrared radiometry (FLIR) data, instream temperature data (hourly), 1:5,000 stream and riparian vegetation (species composition, stand height, and canopy density) data, GISsampling (stream aspect, elevation and gradient, topographic shading, and channel width) and hydrology data (wetted width, velocity and depth profiles) to predict stream temperature at 100 -ft distances for a given day's diurnal conditions in July and August (Oregon Department of Environmental Quality, 2008, 2010). HeatSource uses a finite difference method to solve the nonuniform heat energy transfer equation, which includes consideration of advection, dispersion, and heat energy flux to make stream temperature and energy balance estimates (Oregon Department of Environmental Quality, 2008). HeatSource considers additional heat energy processes such as evaporation, convection, and longwave radiationwhich are not the focus of this research - and it includes solar radiation (direct and diffuse) that is purely an additive processes to stream temperature (in other words, other heat transfer processes can remove heat from streams) and is the current focus of this research as it is cited as the primary source of heat energy to the streams (Oregon Department of Environmental Quality, 2008; Beschta, 1997). In the model, particular spatial parameters of note related to solar loading include: riparian height, canopy density, riparian overhang, topographic shade angle, aspect, elevation, and gradient. The model accounts for riparian growth dynamics with expert opinion from interpreting vegetation communities in historic aerial photographs and the likely canopy composition for present-day geomorphic units and agents of change to riparian vegetation with Monte Carlo simulations of disturbance (Oregon Department of Environmental Quality, 2008). The model does not appear to represent dynamically the process of biophysical state change, which allows for both (1) dynamic improvements with VDDT and (2) consideration of future states of young riparian canopy with facsimiles from other locations of mature, late seral stage riparian stands.

Given that the treatment of heat exchange terms and spatial parameters of thermal loading by others is spatially and mechanistically insufficient to address adequately the problem of cold water refugia in riverine systems, the focus of this research is on $N H$ in equation 1 and $\Sigma N H_{a}$ in equation 2 . This paper uses a spatially explicit, anisotropic, upward-looking, geometric solar radiation model in ArcGIS and is intended for studies of ecological processes (Fu and Rich, 2000, 2002; Rich and others, 1994). This model is considered a topoclimatic model, which is able to produce relatively accurate estimates of temporal and spatial patterns of microclimate, while using readily available topographic data for input. Fundamentally, given a particular DEM surface and for any particular cell, it creates viewsheds of sky obstruction by tracing horizon angles along a specified number of directions (fig. 1). Based on a simple light transmission model (0 to 100 percent), direct radiation received by a cell is calculated from sun 
maps and overlaying the viewsheds on these sun maps, while diffuse radiation is calculated from simple diffuse models for both uniform and standard overcast skies. The topographic derivatives of elevation, slope, and aspect correlate moderately well with insolation, but this more complete insolation model includes the mechanistic effects of surface orientation, elevation, and sky obstruction by surrounding topography and vegetation as they relate to shifting solar angles through the day and season at a particular latitude. Insolation can be integrated for various time periods as specified in the input parameters. The full specification of the model algorithms can be found in Fu and Rich (2002). The model assumes that the contribution of reflected radiation (the smallest proportion of the three types of radiation, namely direct, diffuse and reflected) from surrounding surfaces is negligible and local features - as detailed in equations 1 and 2 - can influence the actual temperature regime in a given packet of water. This is particularly important when relating to the particular habitat requirements of different salmonids and how cold water refugia change over time, space, and climatic regimes (Harte and Shaw, 1995).

\section{Ground Truthing Approaches}

In this section, approaches to ground truthing are discussed. The airborne tools were used in this research, and the on-theground measurements are presented as an alternative approach.

\section{Airborne Tools}

A low-cost, rapid-response airborne system based on an uncooled longwave thermal infrared (TIR) imager (or microbolometer) mounted in the wing of a Cessna 172 was used

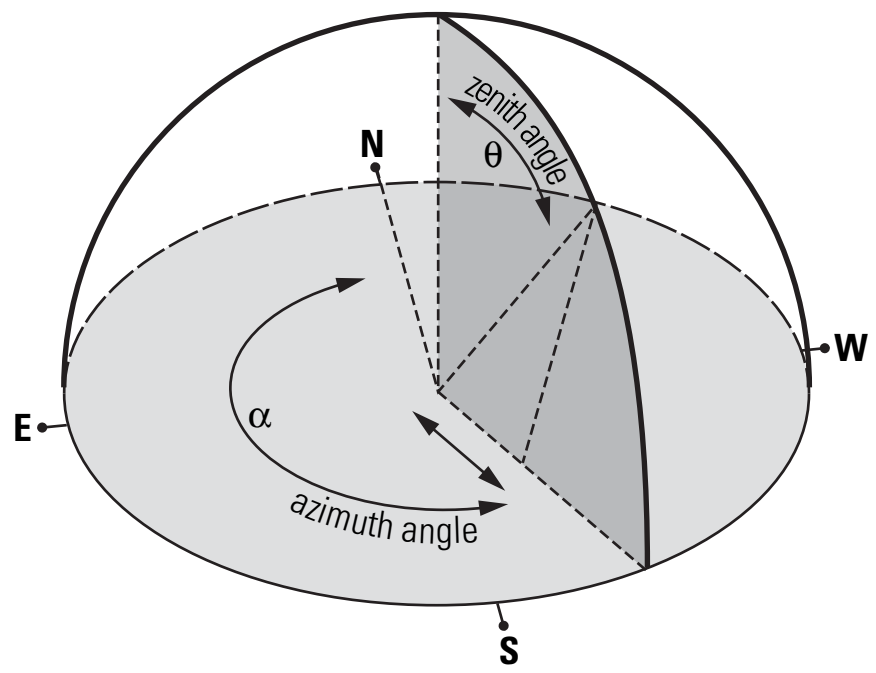

Figure 1. Figure showing hemispherical coordinate system used in the solar loading model and providing the ability to segment the sky into sectors and directions for a given location's calculation. Note: this representation does not include the anisotropy of irradiance due to such factors as watershed, channel or vegetation morphologies. Modified from Rich and others (1994). collect TIR imagery of the water surface over longer reaches of the Klamath River. Airborne TIR imagery offers both extensive spatial coverage and high spatial resolution (for example, Torgersen and others, 2001; Madej and others, 2006), which satisfies the necessary spatial sampling requirements to test the insolation model and to investigate the detailed temperature structure of rivers. The camera used was a $320 \times 240$ focal plane array 14-bit Infrared Cameras Inc. microbolometer (model 7320) with an 18-degree field-of-view lens. In addition to the microbolometer, the system included a visual band red-green-blue camera, a Global Positioning System (GPS), and a moveable ambient temperature reference with a serial-output temperature sensor.

In the air, digital image data are collected at $1 \mathrm{Hertz}$ $(\mathrm{Hz})$, and simultaneous GPS locations are recorded in Universal Transverse Mercator coordinates. Ambient temperature reference images are recorded approximately every 15 minutes, and used to determine the linear correction between raw camera output units (counts) and surface temperature. The camera was postcalibrated in the lab for variable gain due to ambient temperature changes and corrected using inflight system temperature measurements (Nugent, 2008). Individual images were georegistered using standard photogrammetry (Holland and others, 1997) based on GPS locations of the plane and image matching techniques (Foroosh and others, 2002) and combined into mosaicked thermal maps of the river surface.

Recent technological advances in remote sensing of vegetation structure and identification are important to consider. In terms of vegetation structure, LiDAR systems that push into the third dimension (the vertical) have been shown to be successful in measuring crown bulk density, and thus crown volume and foliage biomass (Riaño and others, 2004; Popescu and others, 2003), as well as height, basal area, biomass, stand volume, leaf area index (Hudak and others, 2002), and canopy transmittance (Hopkinson and Chasmer, 2007). These remotely sensed measurements can still require ground truthing with such estimates as tree DBH and tree and crown base height. Although crown bulk density is more often used as an essential modeling parameter for crown fire behavior (Scott, 1999), it can also be used as a measure of light interception capability.

\section{On-the-Ground Measurements}

Davies-Colley and Rutherford (2005) outline three approaches to measuring shade, with a preferred emphasis on the third one: (1) long-term logging of proportional lighting, (2) manual surveying of shading elements, and (3) fish-eyelens imaging of shade's spatial distribution above a given point. Their technique suggested deploying two matched PAR sensors on fully overcast days to give measures of diffuse, nonintercepted light.

For combination of the three techniques, Watercourse Engineering, Inc. (2003) took measurements of baseline (no shade) and reduced (shaded) solar radiation "throughout the Shasta River" twice at two locations during the 2001 field 
season and a simple, basin-wide survey of tree species and height along the river's banks. The baseline and reduced pairing technique has been employed in other studies (Davies-Colley and Payne, 1998; Webb and Zhang, 1997; and Bartholow, 2000). Solar irradiance can be measured with pyranometers, which are of two typical types:

- Thermopiles: capture a wider range of the electromagnetic spectrum and have more accurate cosine response to sun angle and shade, but they cost thousands of dollars (for example, Eppley Precision Spectral Pyranometer).

- Photovoltaics: capture a peak response in the nearinfrared wavelength and not ideal for shade applications, but they cost a few hundred dollars (for example, LI-COR 200 Pyranometer).

Watercourse Engineering, Inc. (2003) collected vegetative transmittance $\left(\mathrm{T}_{\mathrm{r}}\right)$, or percentage of solar radiation passing through the canopy, according to the following relationship:

$$
T_{r}=\frac{I_{\mathrm{V}}}{I_{\mathrm{S}}},
$$

where:

$I_{v}=$ solar radiation under tree canopy or effective barrier $\left(\mathrm{W} / \mathrm{m}^{2}\right)$

$I_{s}=$ unimpeded solar radiation $\left(\mathrm{W} / \mathrm{m}^{2}\right)$

The latter was measured using a photovoltaic-type pyranometer, namely the LI-COR, Inc. LI200 model, while the former was measured using a thermopile-type pyranometer called SOLRAD produced by Kipp \& Zonen, Inc. The latter was stationed at one location for a given sampling point, while the former was stationed at three locations (under trees, cut banks and bulrush) in the river system. The study observed the impact of clouds, but did not account for it in the derivation of $T_{r}$.

Another study suggested the use of the Solar PathfinderTM because it focuses on the portion of the vegetation canopy that blocks direct solar radiation throughout the course of a day (Moore and others, 2005). Shade-inducing objects can be measured with approaches like:

- For a given location and at a single point in time, account for and document obstructions (vegetation) between ground and sun during the sun's path over a year (for example, Wiley Electronics Acme Solar Site Evaluation Tool).

- Obtain leaf area index (LAI), the ratio of foliage area to ground area (for example, LI-COR LAI Plant Canopy Analyzer).

The former Solar Pathfinder-style of instrument appears to have more promise in deriving an index of crown projected foliage and stem cover, while the latter has been demonstrated to have low explanatory power that could possibly arise from difficulty with field techniques. It is important to note that this study did not apply these on-theground measurements, but includes them for the sake of comprehensiveness and as a courtesy to other researchers who may be interested in testing them.

\section{Methods and Materials}

Temporal modeling requirements outlined by the NRC (2008) in the natural-flow study included a specification of daily values for ecological applications. As such, the method used in this model application included half-hour increments integrated over one morning in August 2010. The parameters of this method can be specified to include a finer temporal increment (for example, minutes), as well as a longer period over which to integrate (for example, weeks or months). As outlined in the conceptual schematic (fig. 2), the following three scales and resolutions of raster datasets (field data) were fused to create a multiscaled input surface for the model's execution at the case study site: watershed morphology, fluvial morphology, and vegetation morphology.
Figure 2. Conceptual schematic showing method development and model application. Digital elevation model, DEM.
Inputs

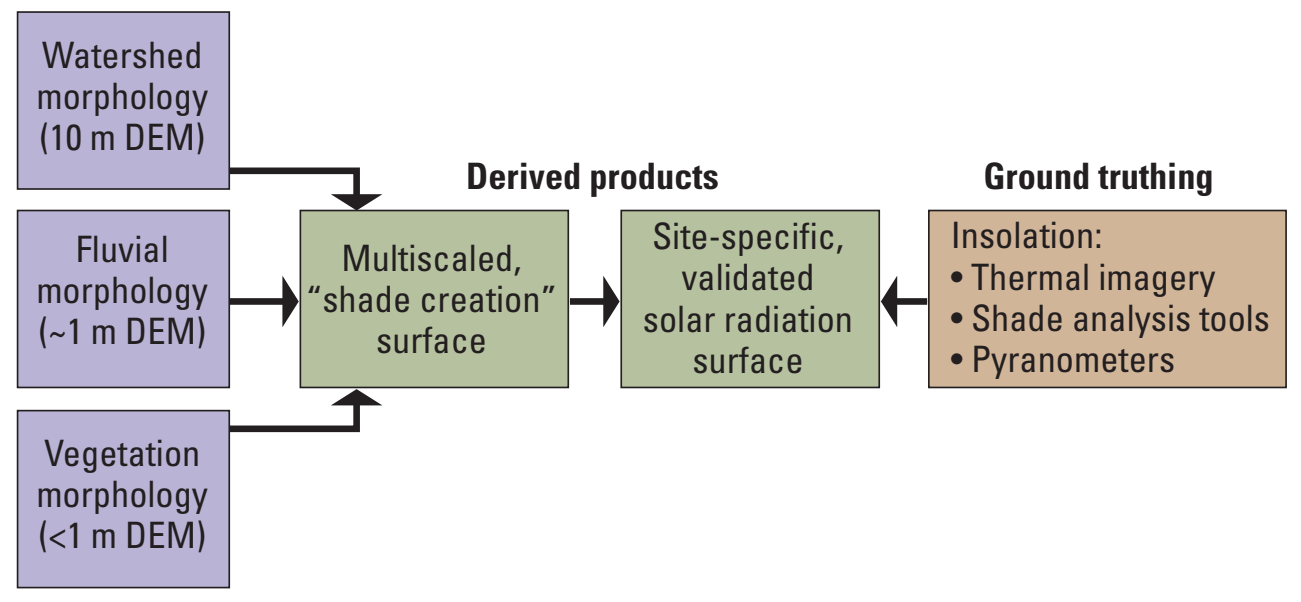




\section{Case Study Site: Confluence of Klamath River Mainstem and Scott River}

Situated in the Klamath National Forest, the study reach of the Klamath River is well below Iron Gate Dam - the last of a series of dams that hydrologically disconnect the lower basin from the upper basin. An overview of the study site is shown in figure 3 . The northern ridgeline of the watershed is part of the Siskiyou Mountains coinciding with a segment of the Pacific Crest Trail, and the southern ridgeline is part of the Marble Mountains. The southern ridgeline is approximately $7 \mathrm{~km}$ long, with elevations between approximately 1,830 and 2,100 $\mathrm{m}$, and the peak-Tom Martin Peak of the Marble Mountains - stands at 2,140 $\mathrm{m}$. The elevation profile of the Klamath mainstem ranges from approximately $430 \mathrm{~m}$ on the west side to $510 \mathrm{~m}$ on the east side. Stage and discharge for the Klamath River for the week before and after the TIR flight are shown in figure 4; the site is the USGS stream gage near Seiad Valley (gage 11520500), almost $4 \mathrm{~km}$ downstream of the study area. The 4-month average discharge for July through October, 2010, was $37.6 \mathrm{~m}^{3} / \mathrm{s}$. During the morning of the TIR flight and the cumulative loading calculated by the solar models, August 26, 2010, discharge ranged from 32.25 to $32.5 \mathrm{~m}^{3} / \mathrm{s}$ and stage was about $0.65 \mathrm{~m}$. Primary California vegetation types and land covers in the watershed include: agriculture, Douglas fir (Pseudotsuga menziesii), Shasta red fir (Abies magnifica) and white fir (Abies concolor), ponderosa pine (Pinus ponderosa), Jeffrey pine (Pinus jeffreyi), western white pine (Pinus monticola), northern mixed chapparal, montane mixed chapparal and hardwoods, mixed Douglas fir and pine, mixed Douglas and white fir, mixed conifers (pines, firs and others), canyon live oak (Quercus chrysolepis), Oregon white oak (Quercus garryana), California black oak (Quercus kelloggii), white alder (Alnus rhombifolia) and mountain alder (Alnus incana ssp. tenuifolia), huckleberry and blueberry (Vaccinium sp.), buckbrush (Ceanothus cuneatus), annual grasses/forbs, wet meadows, and barren rock. Particular vegetation types that are likely to be more important in terms of riparian shading are: willow species (Salix sp.), red and white alder, mixed riparian hardwoods, Fremont's and black cottonwoods (Populus fremontii and trichocarpa, respectively), bigleaf maple (Acer macrophyllum), and various pines that can tolerate more mesic sites. According to the Federal Emergency Management Agency (FEMA) flood zone maps, the widths of the Klamath floodplain ranges from approximately 50 to $550 \mathrm{~m}$.

\section{Watershed Morphology}

Mason (1983) included azimuth, elevation angles, and topography of surrounding hills to integrate diffuse (typically 20 percent on a clear day, and 100 percent on overcast days) and direct radiation to small reservoirs over diurnal and seasonal timeframes. In this case as the LiDAR data did not have sufficient extent to cover the watershed, the USGS 10-m DEM was used as the input to derive topography, elevation, and aspect related to the magnitude of light

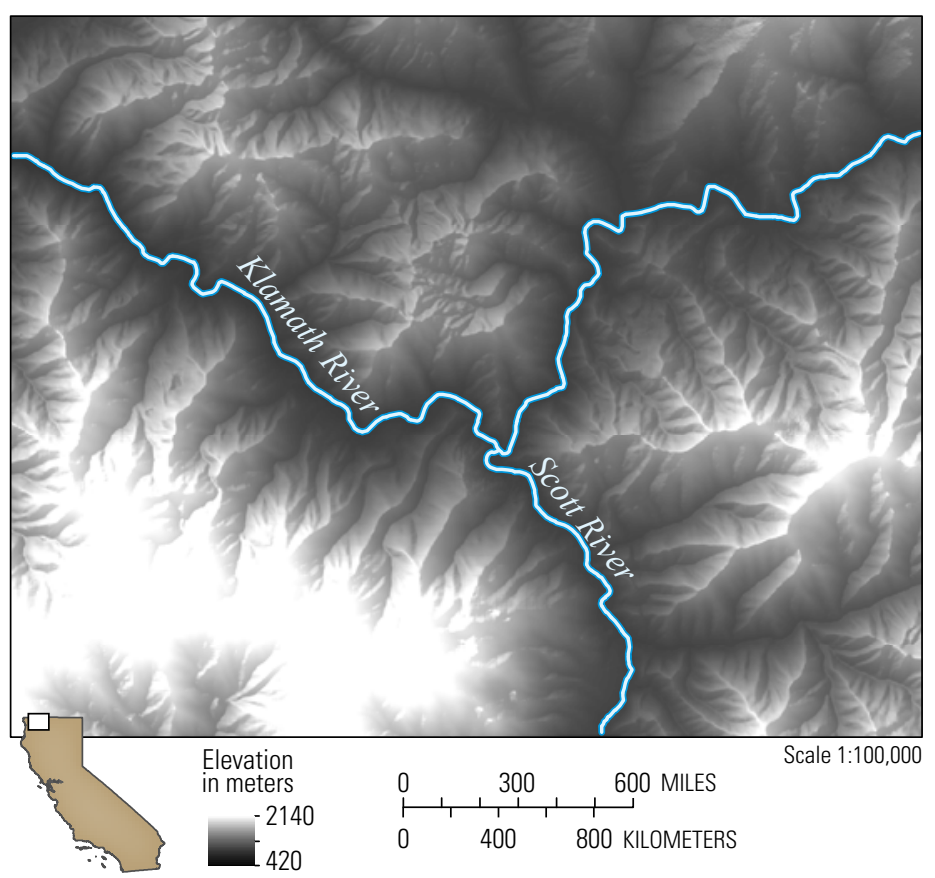

Figure 3. Map showing the study site and model input extent. Elevation data sources are a composite of LiDAR-derived products from the Bureau of Reclamation and the U.S. Geological Survey National Elevation Dataset.

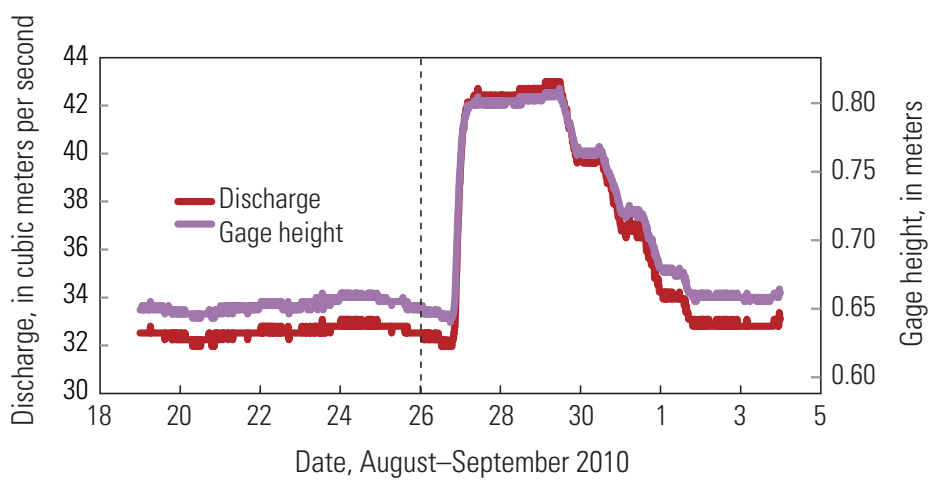

Figure 4. Plot showing hydrograph of discharge and gage height on the Klamath River at Seiad Valley, more than 4 kilometers downstream of the study area. Period includes the week before and after the solar loading models and thermal infrared flight on August 26, 2010 (indicated by dashed line). Data source is the U.S. Geological Survey National Water Information System. 

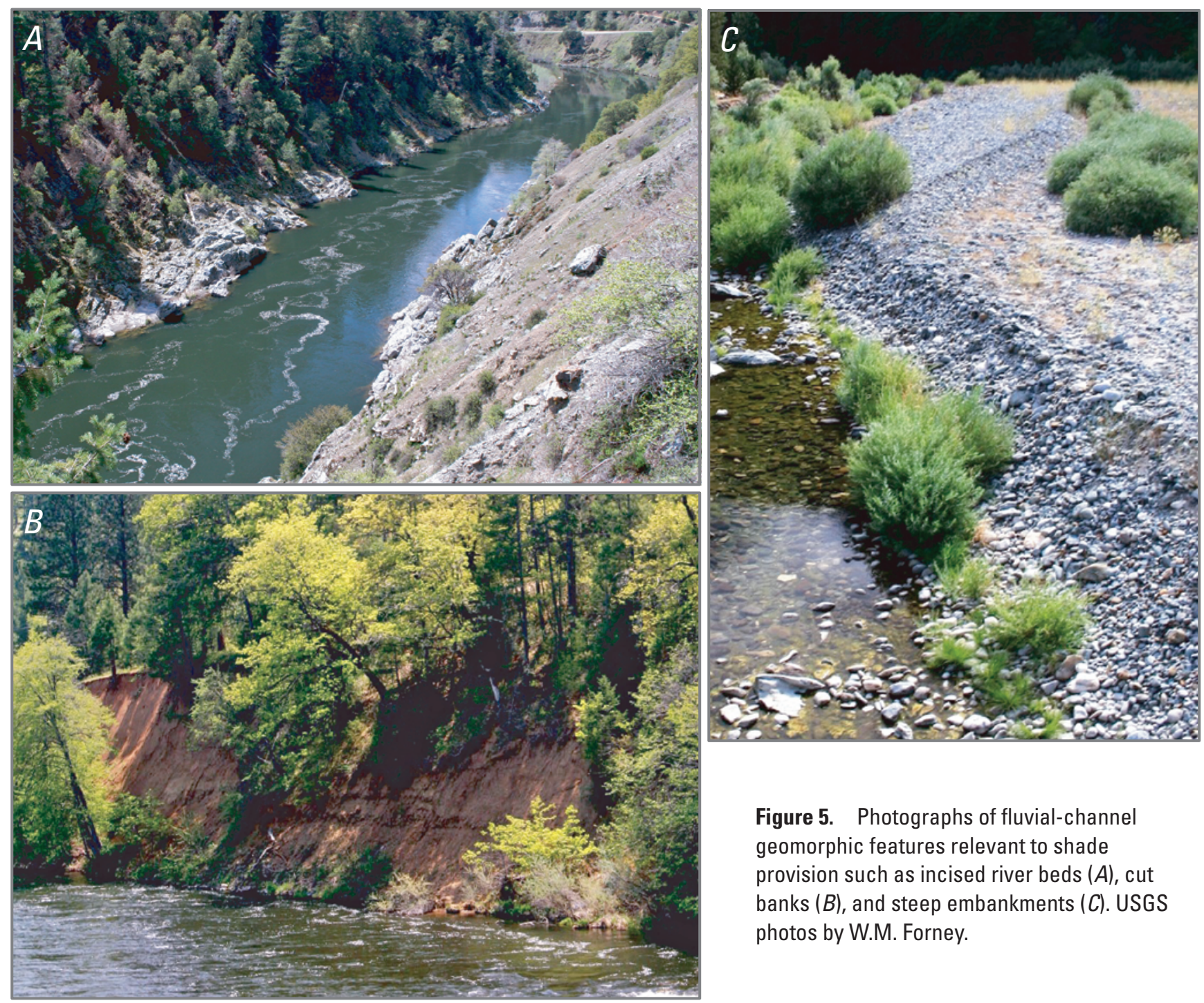

Figure 5. Photographs of fluvial-channel geomorphic features relevant to shade provision such as incised river beds $(A)$, cut banks $(B)$, and steep embankments $(C)$. USGS photos by W.M. Forney.

transmission from the sun. This included additional important features such as ridgelines, canyon orientation, and hillslope.

Cloudiness or atmospheric transmittance can be estimated using maximum and minimum air temperature and location specific, empirical coefficients (Bristow and Campbell, 1984), as is done in Flint and Flint (2008). An improvement on this technique is to use the archive of moderate resolution imaging spectroradiometer (MODIS) satellite data and its Aqua and Terra sensors to estimate cloud cover more directly in terms of its transmittance of the electromagnetic spectrum. Given the availability of the dataset of thermal imagery for the morning of August 26, 2010, the archive was referenced for that day and estimates of 70 percent transmittance (the ratio of energy received at the upper atmosphere to that which reaches Earth's surface) and 20 percent diffuse radiation were made for input into the solar insolation algorithm, both of which are typical for a relatively clear day. These values were used as inputs to the parameter set for the solar loading model.

\section{Fluvial Morphology}

Defining the floodplain and its channel geomorphic features ought not to be done according to a standard buffer distance, but on flood frequency maps (Muller, 1997). Although stage-discharge relationships can be established in many locations with the existing set of gaging stations, without improved data for the detailed microtopography of the floodplain and (or) better modeling of the in-stream hydrodynamics of the system, the best estimate of spatially explicit flood extents are the FEMA flood maps that include estimates of the extents of the 1-, 10-, 50-, and 100-year events. This provides a measure of quality control, and it defines the geographic boundary for the floodplain area of interest. Given the availability of LiDAR-derivate data that could capture fluvial geomorphic features from the U.S. Bureau of Reclamation (USBR), namely the bare earth model, the extent defaulted to what was available (table 1). This situation is satisfactory, as not all of the bedform features of 
Table 1. Spatial datasets used in the manuscript.

[Note: original projections of spatial datasets vary; USBR, U.S. Bureau of Reclamation.]

\begin{tabular}{|c|c|c|c|c|}
\hline Name & Source & Scale & Resolution & Usage \\
\hline $\begin{array}{l}\text { Digital Elevation Model } \\
(\mathrm{DEM})\end{array}$ & U.S. Geological Survey & Subwatershed to watershed & 10 meters & Model input \\
\hline $\begin{array}{l}\text { Vegetation Canopy Structure } \\
\text { (VCS) }\end{array}$ & $\begin{array}{l}\text { Derived from LiDAR } \\
\text { data of the USBR }\end{array}$ & Same as Channel Bare Earth Model & 0.3 meters & Model input \\
\hline $\begin{array}{l}\text { Thermal Infrared Imagery } \\
\text { (TIR) }\end{array}$ & $\begin{array}{l}\text { Applied Physics Laboratory, } \\
\text { University of Washington }\end{array}$ & $\begin{array}{l}\text { Riverbank to riverbank within } 1 \mathrm{~km} \text { of Scott River } \\
\text { confluence, collected 9:04 a.m., August 26, } 2010\end{array}$ & $\begin{array}{l}0.75 \text { meters } \\
\text { (raw resolution) }\end{array}$ & $\begin{array}{l}\text { Model } \\
\text { validation }\end{array}$ \\
\hline Floodplains & $\begin{array}{l}\text { Federal Emergency } \\
\text { Management Agency }\end{array}$ & $1: 24,000$ & & $\begin{array}{l}\text { Input } \\
\text { verification }\end{array}$ \\
\hline
\end{tabular}

the floodplain will influence solar loading dynamics - for example, a relic sediment deposition feature such as a sandbar that is a result of a 50 -year flood event. Depending on their location and relationship to the path of the sun, features that are more important to capture are steep scarps, bedrock outcrops, cobble banks (either natural or human-installed) particularly on the southern side of the river - that can provide local pockets of shading (fig. 5).

\section{Vegetation Morphology}

Similar to the reasoning above, although the FEMA flood zone map can provide a maximum extent for the vegetation of interest, it is less directly relevant due to the fact that tall trees outside of the floodplain can still provide shade to the river. Furthermore, the available LiDAR data establishes the boundary condition by default. Figure 6 provides examples of where vegetation such as stream-side willows, cottonwoods, alders, and bigleaf maples in the active floodplain, and evergreens (like Douglas fir, ponderosa pine, and oaks) in the active floodplain and canyon banks provide shade to the river system.

\section{Data and Fusion of Multiscale Surface}

The data used in this report are described in table 1. The techniques for creating the multiscaled surface are multistepped and require the following software packages: ArcGIS, ENVI, Erdas IMAGINE, MatLab, InnovMetric Polyworks, and Golden Software's Surfer. For the watershed morphology, the USGS 10-m DEM was selected and downloaded from the National Map (http://nationalmap.gov/viewer.html, accessed Dec. 18, 2012). A custom bounding box was created for clipping to the extent shown in figure 3 , which ensured that the ridgeline and peak south of the focal area were included. The
DEM was reprojected to California State Plane Fipzone 0401 (UTM Zone 10), as were the LiDAR-derivatives channel bare earth model (CBEM) and vegetation canopy structure (VCS).

The CBEM processing was completed and provided by the Bureau of Reclamation (Wright, 2010) as an ArcGIS grid. Considering the focal area of the Scott River confluence, eight tiles of raw LAS files (standard LiDAR data file format) from the Airborne LiDAR returns were processed to create the VCS (fig. 7). This was done by stripping the point returns that were interpolated to be near the ground surface, and isolating point returns at a height $15 \mathrm{~m}$ above the ground. Once these XYZ points (where $\mathrm{Z}$ represented the tree height) were isolated, the ASCII points were interpolated to a $0.3-\mathrm{m}$ continuous grid. In order to create a surface that had gaps in the canopy so that light could penetrate through the canopy structure, the ASCII points were also plotted as a simple grid surface (values 0 and 1) to create a mask for the presence/absence of canopy. ENVI software was used to apply the mask to the interpolated grid file, rendering the final VCS file. Projected XYZ points were converted to a universal format using Surfer, then interpolated to a 1-m raster surface using ENVI.

Once the VCS was in ArcGIS as a grid file, we used a conditional statement to combine the VCS with the CBEM so that the tallest values (in other words, the vegetation canopy) were preserved, and the channel morphology was represented in the rest of the locations where vegetation was not present. This created a grid surface that combined the VCS and CBEM of the high-resolution, high-accuracy LiDAR products into one dataset for the area around the Scott and Klamath River confluence. This combined product was mosaicked with the lower resolution, lower accuracy, larger extent DEM while preserving the highest elevation values, which provided a multiscaled representation of the watershed, channel, and vegetation morphology. It should be noted that down-sampling the USGS 10-m DEM does not improve the resolution of the 

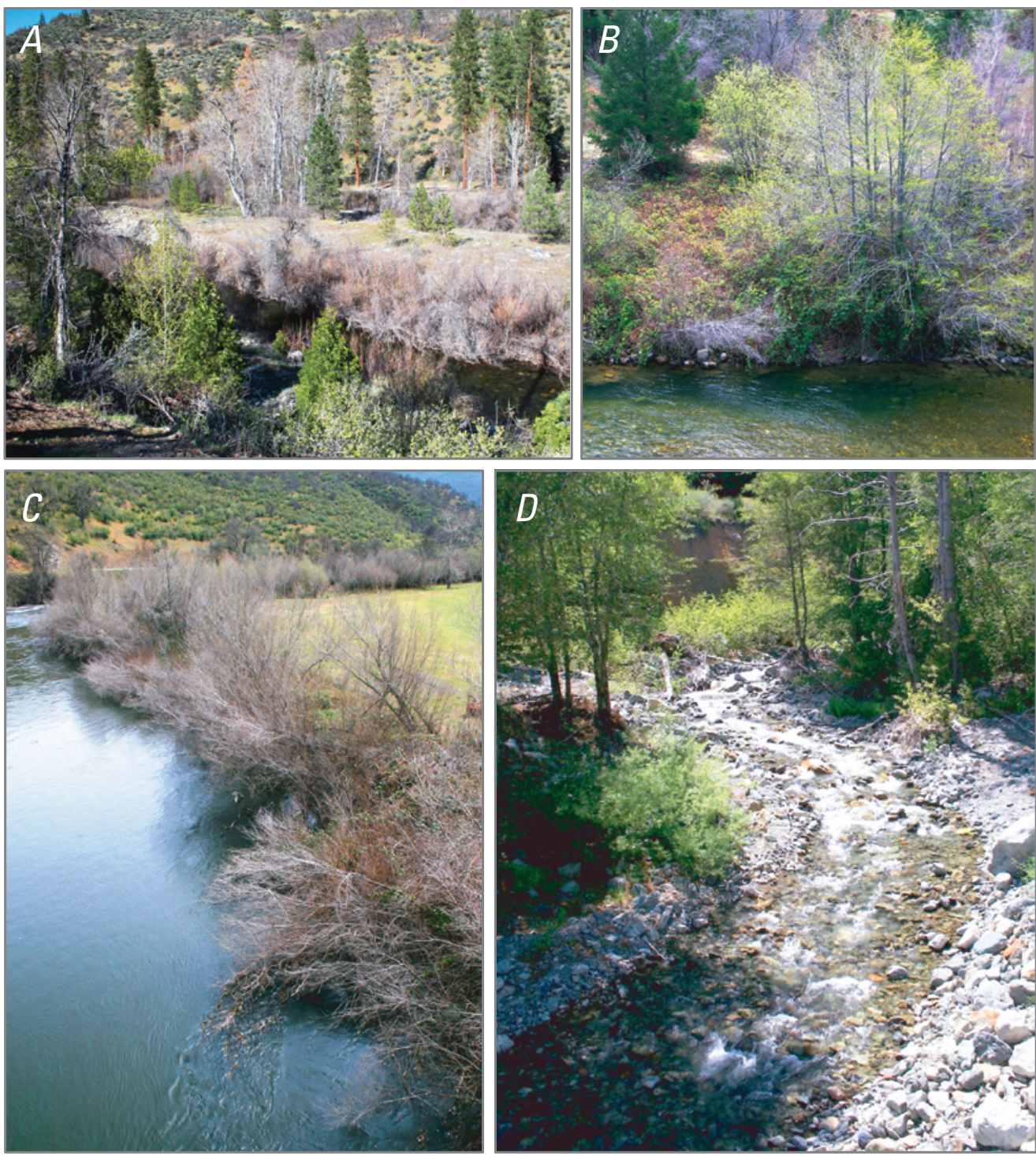

Figure 6. Photographs of vegetation morphology and contexts relevant to shade provision such as willows along banks $(A$ and $C)$, overhanging riparian canopy $(B, C$, and $E)$, and tall vegetation set back from channel $(A$ and $D)$. USGS photos by W.M. Forney.

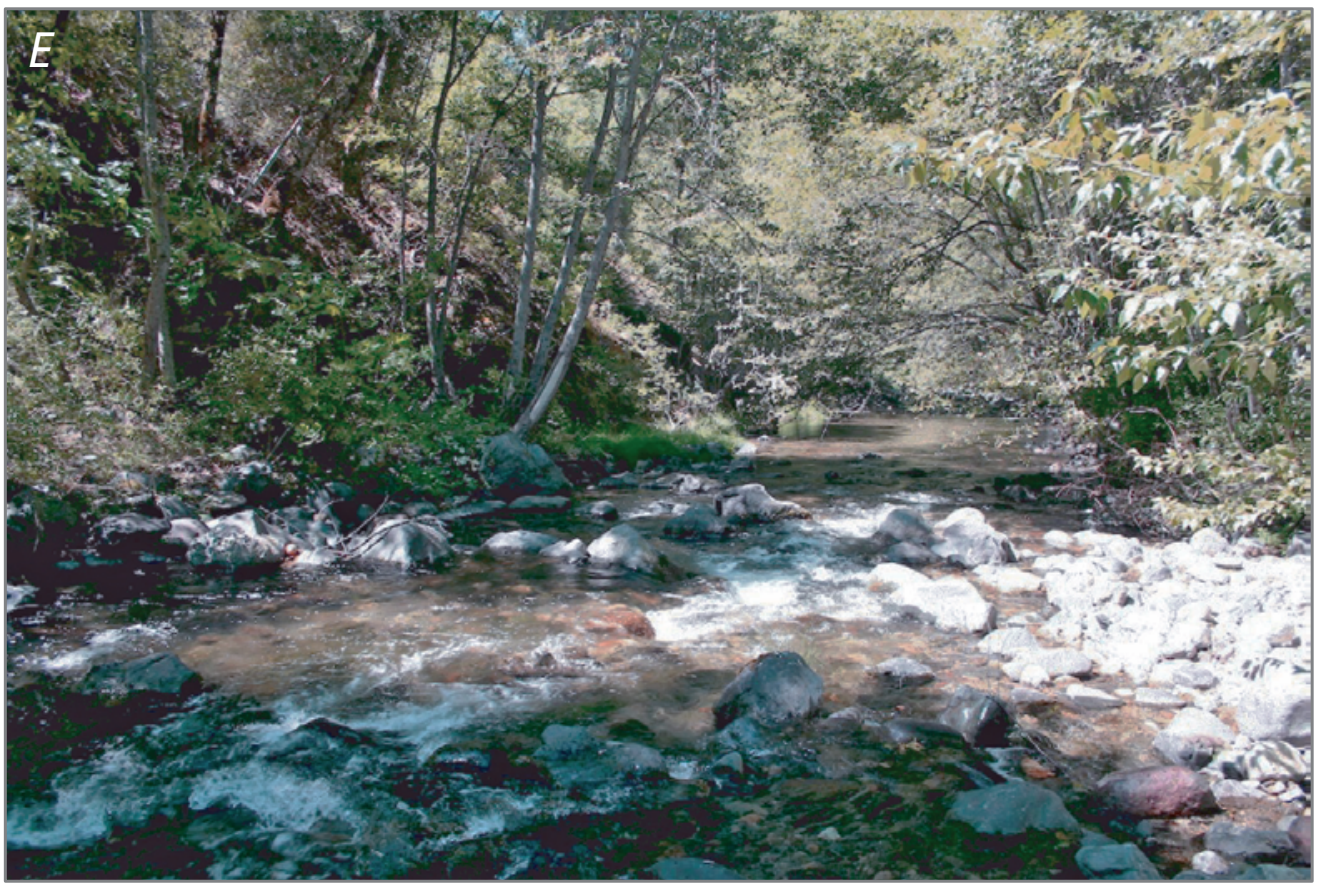


data. It is necessary make a consistent grain size for the multiscaled grid and to gap-fill those areas without LiDAR-based data. This multiscaled grid was used as the input to the solar radiation algorithm of ArcGIS. For the purposes of comparison and model validation, three different versions of the multiscaled grid were created to produce three outputs. The versions varied in their processing techniques: one averaged the elevation values during the combination of the VCS, CBEM and DEM (Solar Model 1, fig. 8), one maintained the highest elevations during the combination (Solar Model 2), and the last maintained the highest elevations of the three surface inputs and resampled the three grids directly to $3 \mathrm{~m}$ before mosaicking and running the model (Solar Model 3, fig. 9). The previous two models were resampled beyond the final resolution target to $0.3 \mathrm{~m}$ (the native resolution of the data provided by USBR before being aggregated up to $3 \mathrm{~m}$. The three different processing routines provided three different model outputs for comparison and statistical analysis of the results.

\section{Thermal Infrared Imagery}

For the Scott River confluence, the airborne TIR was collected on August 26, 2010, beginning at 8:57 Pacific daylight time (fig. 10). The TIR system was flown at a nominal altitude of $760 \mathrm{~m}$ above ground level and along the river in overlapping, linear segments to fully map the site of interest. The total flight covered more than $6 \mathrm{~km}$ of total river length and was completed in less than 15 minutes, minimizing temporal changes due to surface heating. At the nominal altitude, the camera view spanned approximately $240 \mathrm{~m}$ by $180 \mathrm{~m}$ with an average pixel resolution of $0.75 \mathrm{~m}$.

In addition to temperature calibration and georegistration, each TIR snapshot was autonomously analyzed to segregate river pixels from land and vegetation. A simple threshold method was developed based on the temperature variability. The span of temperature in a 5-pixel neighborhood around each image pixel was calculated, and pixels with a temperature span less than $0.5^{\circ} \mathrm{C}$ were set as "river" pixels. Small patches of low span usually corresponded to regions between trees, so the largest group of "river" pixels were retained (all others were removed from analysis). The choice of the $0.5^{\circ} \mathrm{C}$ variance threshold span was arbitrary based on trial and error to isolate river-only portions of the TIR imagery. Because the same threshold was used for the entire data set, the overall analysis and data partitioning is objective. Some snapshots corresponding to views without any sections of the river had to be manually removed. The remaining images of river-only pixels were interpolated to $1-\mathrm{m}$ resolution for a 0.9 - by $0.5-\mathrm{km}$ map of the Scott-Klamath confluence.

\section{Statistical Analyses}

The statistical analyses were conducted in the software packages R, Octave, and ArcGIS. For the TIR resampling technique, the analyses included bilinear interpolation from neighboring cells - some valued at the no data default of -9999 — which resulted in the inclusion of temperature values below those found in the original measurements of TIR (below 18.16 degrees Celsius). Those lower values were considered outliers and removed from statistical analyses $(n=5,222$ for the TIR). As a requirement of ArcGIS's sampling routine, the surfaces were resampled to $3 \mathrm{~m}$ with bilinear interpolation (which is more appropriate with continuous values). From the TIR surface, a mask was created where temperature values were present, and it was used to extract the TIR grid cell values and the three solar loading grid cell values to the various statistical packages, as well as the grid cell's geographic coordinates.
Figure 7. Vegetation canopy morphology derived from airborne LiDAR and shown at an oblique angle at the confluence of the Scott and Klamath Rivers. Dark green is greater than 30.5 meters in height, light green is 15.25 to 30.5 meters in height, brown is below 15.25 meters in height, and gray is no data. Original data from Patrick Wright, Bureau of Reclamation.

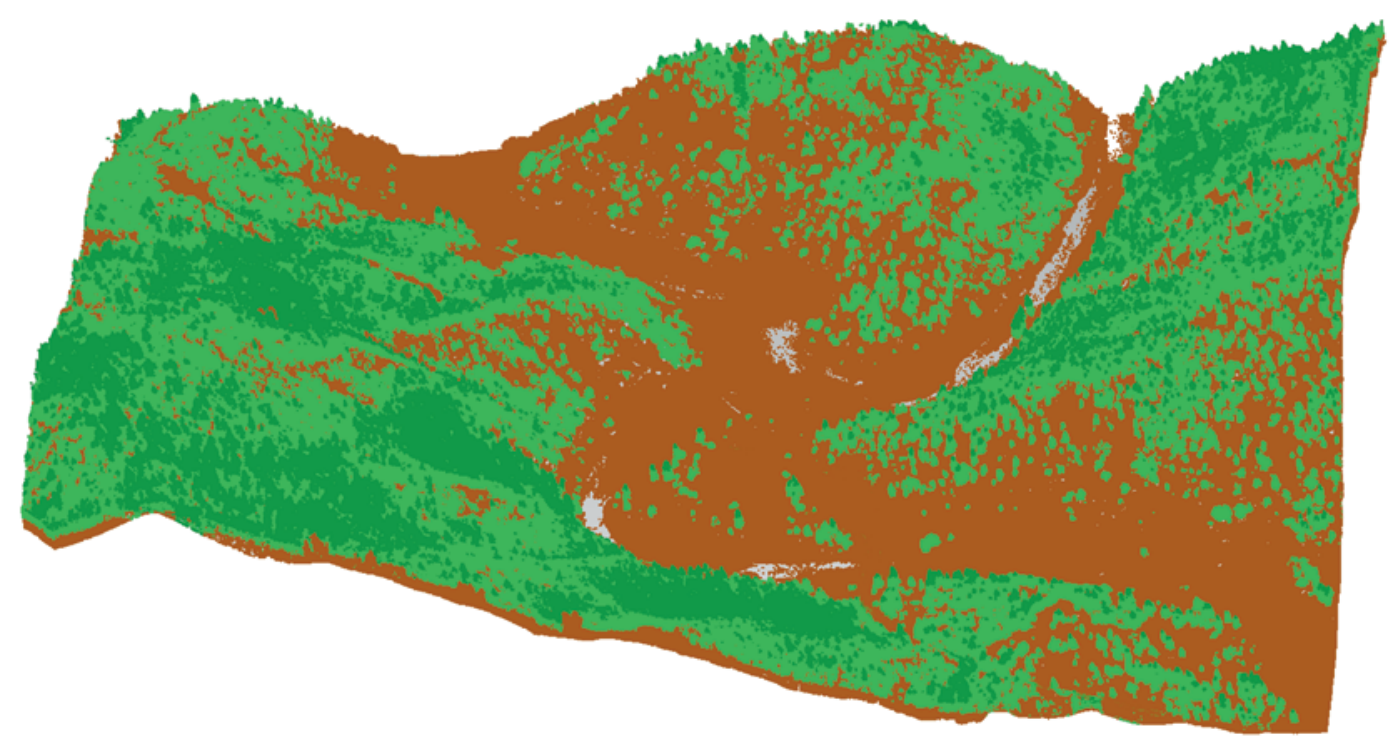




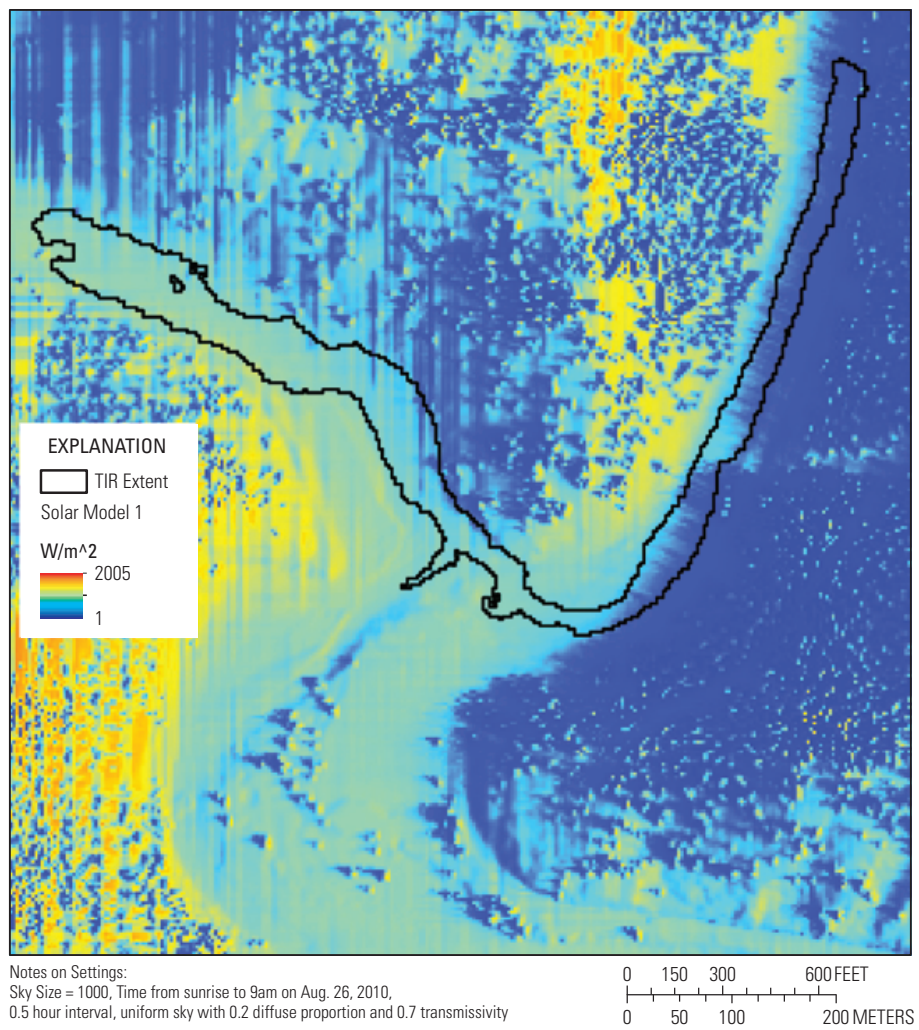

Figure 8. Map of solar loading and Solar Model 1 output for the Scott River confluence with the Klamath River. Thermal infrared, TIR; watts per square meter, $\mathrm{W} / \mathrm{m}^{2}$.

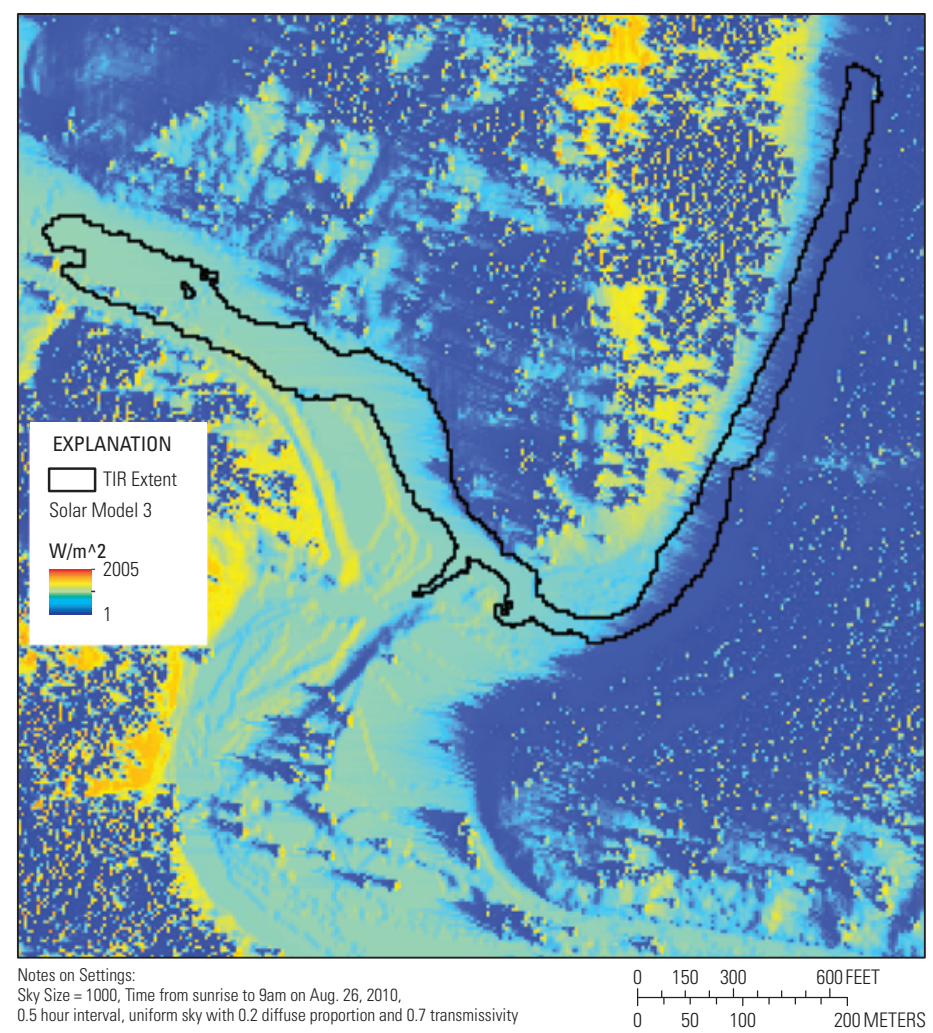

Figure 9. Map of solar loading and Solar Model 3 output for the Scott River confluence with the Klamath River. Thermal infrared, TIR; watts per square meter, $\mathrm{W} / \mathrm{m}^{2}$.

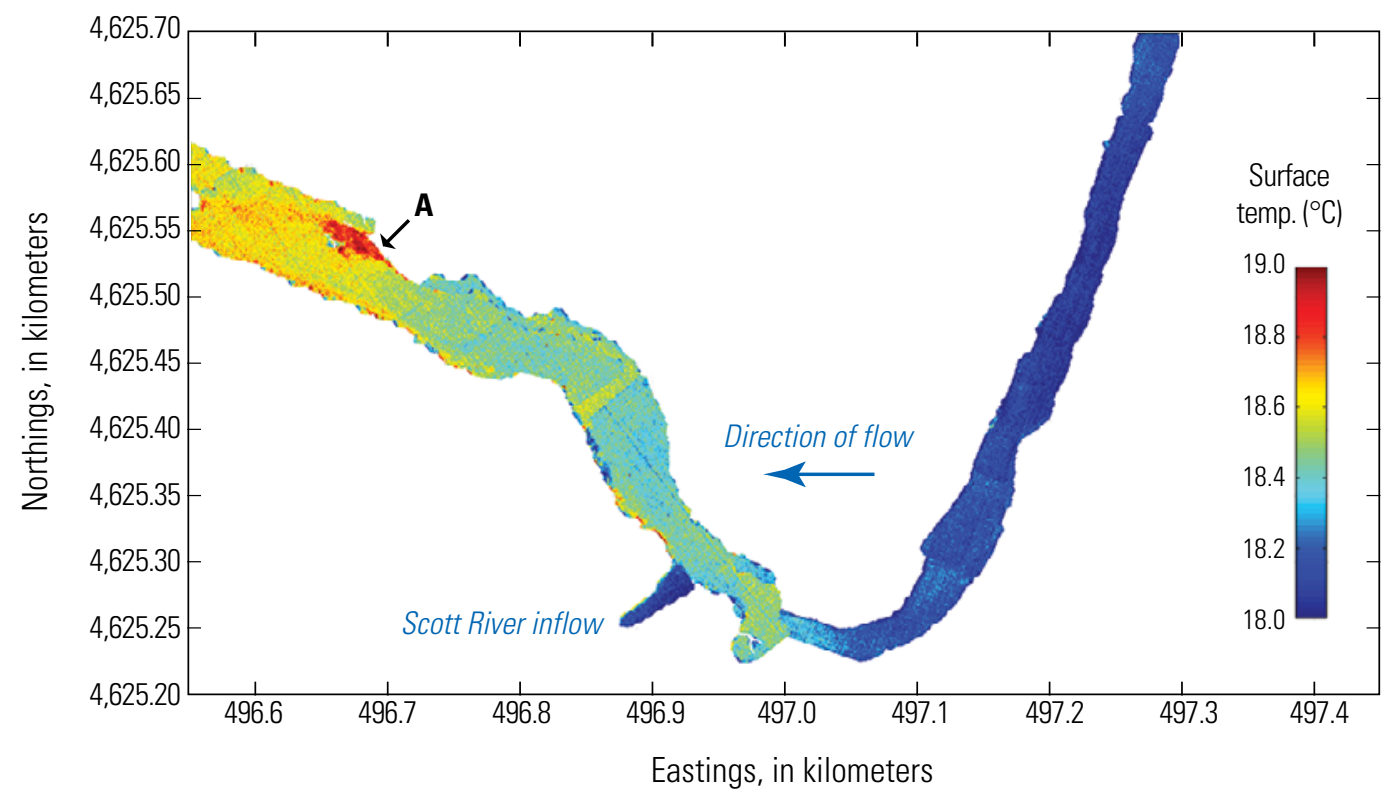

Figure 10. Graphic showing the calibrated river-surface temperatures via airborne thermal infrared imaging at the Scott River confluence with the Klamath River. Point A is a patch of warm temperartures not predicted by the solar loading models. Data are from $\mathrm{C}$. Chris Chickadel, University of Washington. 
To see the distribution of the shading model results within the extent of the TIR flight, scatter plot comparisons with the TIR values on the x-axis were created (fig. 11). The results of the TIR flight were used to validate the output of the solar radiation algorithm. Quantile-quantile plots were used to test for a normal distribution (fig. 12). Given their results, Kendall's tau and Spearman's rho (nonparametric tests of correlation) were used. Each of the three sets of solar loading grid cell values were tested against the TIR grid cell values to find their two values of correlation coefficients and levels of significance. It is worth noting that the units of the two datasets are different, but that does not impact their relative values and correlation comparison.

An important assumption of both Kendall's and Spearman's rank is that the data are randomly distributed. Considering the thermodynamic processes of both the temperature within the river (eq. 2) and insolation loading, it is reasonable to assume autocorrelation in the four datasets at a given point with respect to its neighbors, which would then influence the correlation between the four datasets. In terms of the autocorrelation, one of the most common ways to test if spatial interactions change through the space of a given dataset is the semivariogram $\gamma(h)$, which measures the spatial autocorrelation and indicates how it decreases with distance:

$$
\gamma(h)=\frac{1}{2|N(h)|} \sum_{N(h)}\left(z_{i}-z_{j}\right)^{2},
$$

be an isotropic, onmidirectional scalar (without directional dependence) or anisotropic, unidirectional vector (with directional dependence; Rossi and others, 1992; Pascual and Zhang, 2006; Ciannelli and others, 2008), which can be addressed by rook, bishop, and queen chess piece directionality segmentation (Real and McElhany, 1996) or more finely with particular search angles. The covariogram $C(h)$ is the covariance of $z$ values at separation $h$, for all $i$ and $i+h$ within the maximum distance of the extent of the data field.

$$
C(h)=\operatorname{cov}(Z(i+h), Z(i)),
$$

Correlograms, $\rho(h)$ - the geostatistical equivalents of basic correlation that include the distance lag, $h$ - are the ratios of two covariances,

$$
\rho(h)=\frac{C(h)}{C(0)}=1-\frac{\gamma(h)}{C(0)},
$$

where $C(0)$ is the variance of the random field.

Correlograms are used to test a dataset's spatial autocorrelation against another dataset known to be random. It is suggested to compute variograms, covariances, and correlograms simultaneously as variograms assume constant means and variances through the sampling space. Comparisons of the results can inform lag-to-lag spatial variability and regional patterns due to the changes in local means and variances (Rossi and others, 1992).
Where $N(h)$ is the pairwise set of Euclidean distances $i-j=h$ is also known as a spatial lag, $|N(h)|$ is the number of distinct pairs within $N(h)$ separated by distance $h$, and $z_{i}$ and $z_{j}$ are the values of the response variable at spatial locations $i$ and $j$. Small values suggest clumping and similarity at close distances, whereas large values suggest discontinuous data that are dissimilar and at greater distances (Rossi and others, 1992). This technique requires the consideration of two guidelines in its application: (1) the distance of the variogam's reliability is less than half the distance of the entire extent of the data field, and (2) empirical variograms ought to only be produced with more than 30 to 50 data point pairs on a map (Crawley, 2007; Rossi and others, 1992).

Semivariograms also estimate the range, or distance at which the autocorrelation drops away, or the asymptotic limit on y-axis value of the semivariogram and nugget, or the $\mathrm{y}$-axis distance from 0 that represents the unaccountable spatial variability at distances smaller than the smallest sampling distance. Semivariograms can

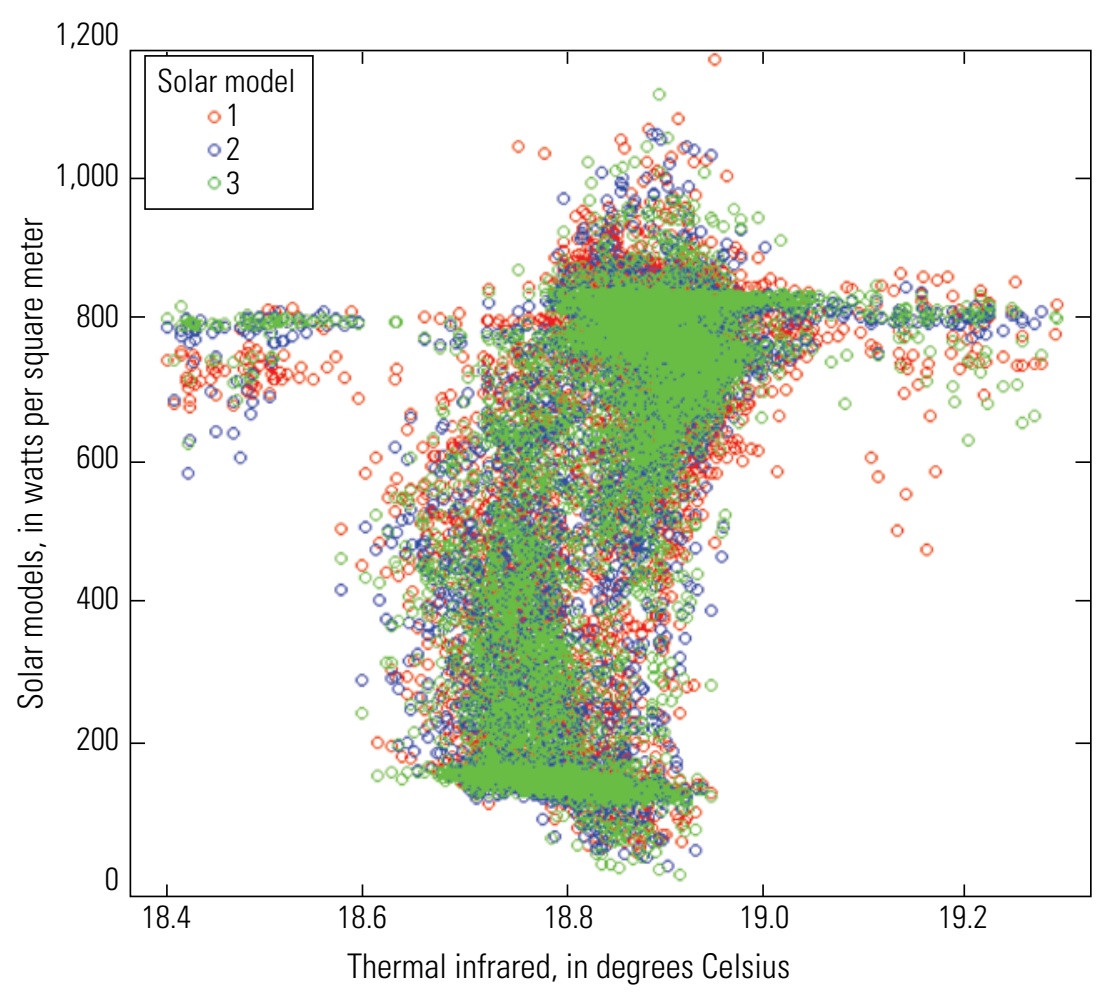

Figure 11. Scatterplot of thermal infrared imagery against three differently processed solar loading models. 


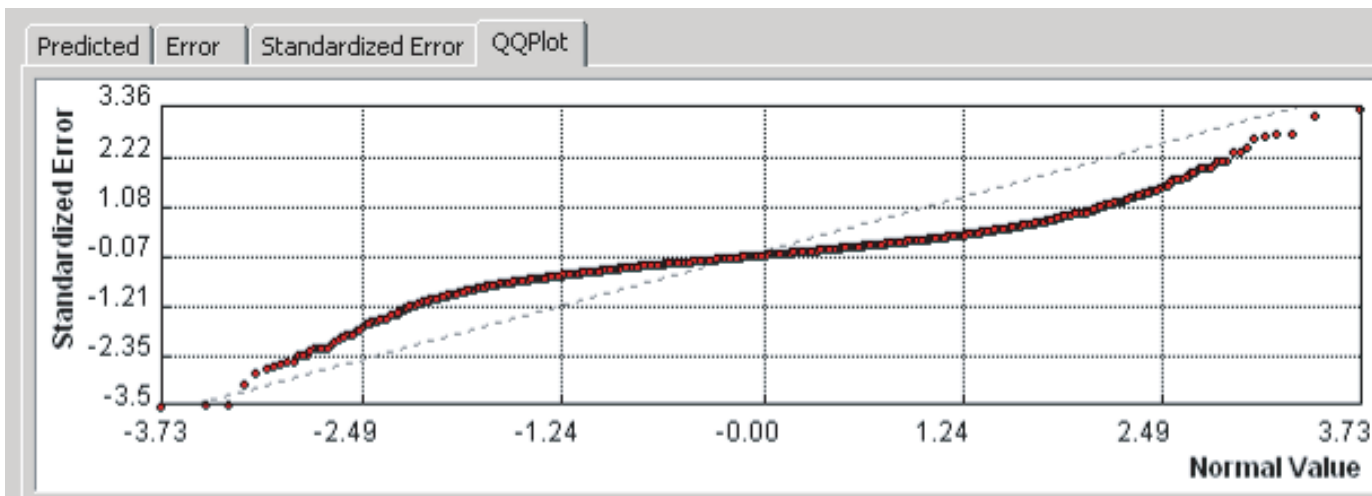

\section{A. TIR}

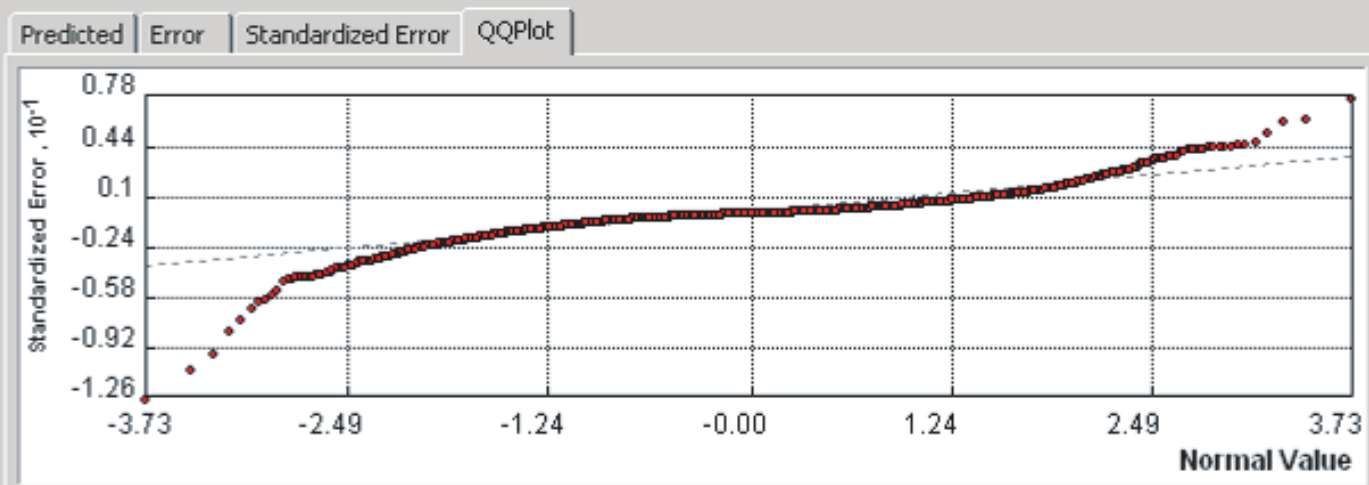

\section{B. Solar Model 1}

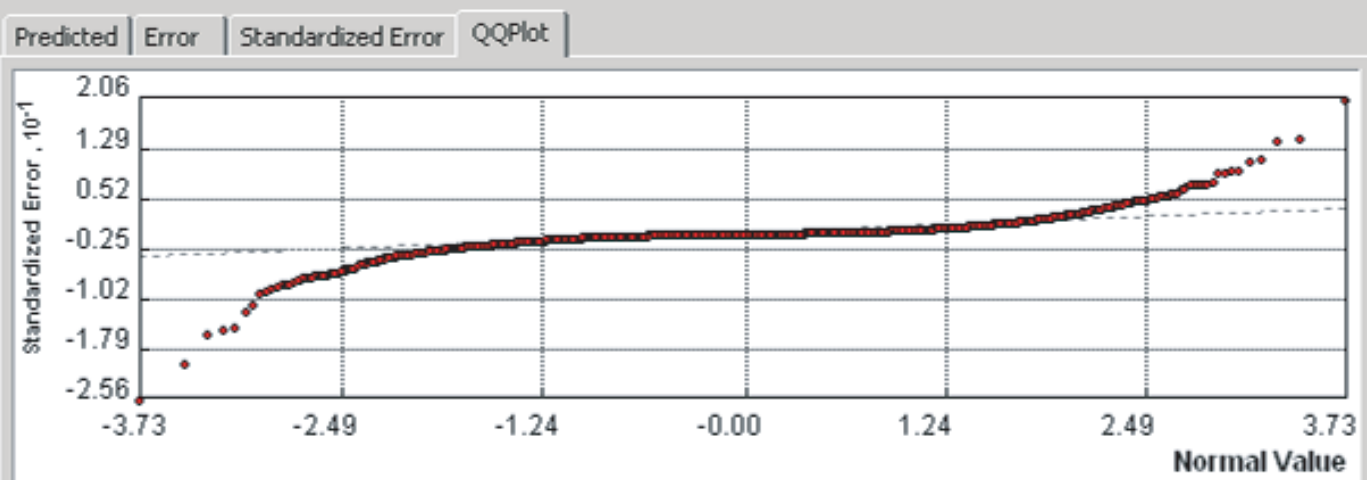

\section{Solar Model 2}

Figure 12. Quantilequantile plots for $A$, the thermal infrared imagery, and $B-D$, three solar loading models at the Scott-Klamath River confluence. S-shaped plots indicate a violation of normality.

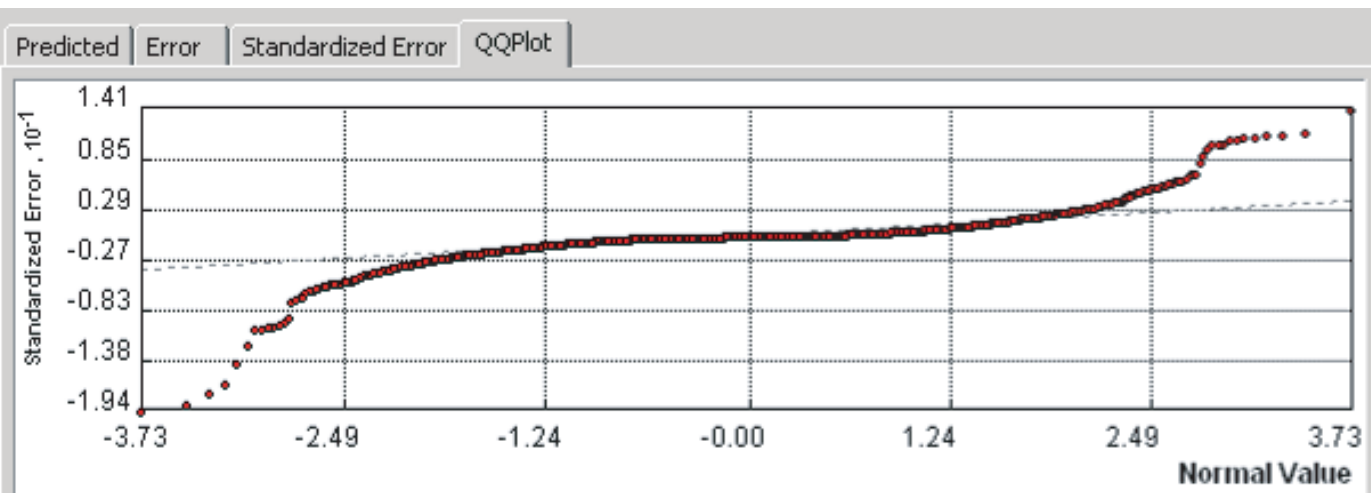

\section{Solar Model 3}


Table 2. Nonparametric correlation tests between 3 differently processed solar loading modes and thermal infrared data for the Scott-Klamath River convluence, August 26, 2010.

\begin{tabular}{lcc}
\hline \multicolumn{1}{c}{ Solar model and test' } & $\begin{array}{c}\text { Correlation } \\
\text { coefficient }\end{array}$ & p-value \\
\hline (a) Solar model 1 - Kendall's rank & 0.3252 & $<0.0001$ \\
(b) Solar model 2 - Kendall's rank & 0.3479 & $<0.0001$ \\
(c) Solar model 3 - Kendall's rank & 0.3497 & $<0.0001$ \\
(1) Solar model 1 - Spearman's rank & 0.5326 & $<0.0001$ \\
(2) Solar model 2 - Spearman's rank & 0.5584 & $<0.0001$ \\
(3) Solar model 3 - Spearman's rank & 0.5558 & $<0.0001$ \\
\hline
\end{tabular}

${ }^{1}$ Each Solar Model was tested against the TIR data.

Variograms, covariances, and correlograms, however, do not test for the spatial covariation between two datasets for any lag distance $(h)$. To do that requires the estimation of the crossvariogram, cross-covariogram, and cross-correlogram. The crossvariogram, $\hat{\gamma}_{A B}(\boldsymbol{h})$, estimates that with the following equation (adapted from Vauclin and others, 1983; Real and McElhany, 1996):

$\hat{\gamma}_{A B}(\boldsymbol{h})=\frac{1}{2 N(\boldsymbol{h})} \sum_{i=1}^{N(\boldsymbol{h})}\left[z_{A}\left(x_{i}\right)-z_{A}\left(x_{i}+\boldsymbol{h}\right)\right] \cdot\left[z_{B}\left(x_{i}\right)-z_{B}\left(x_{i}+\boldsymbol{h}\right)\right]$

where $z_{A}\left(x_{i}\right)$ is one dataset's value (for example, TIR) at location $x_{i}$, and $z_{B}\left(x_{i}\right)$ is the other dataset's value (for example, Solar Model 1) at the same location and the $i$ th observation is included in the summation only if an observation occurs at location $x_{i}+h$ (Lark, 2003).

A simplified version of the cross-variogram that tests covariance of populations of blue mussels at two distinct locations is presented by Smith and others (2009). The crossvariogram does not, however, discern the order and direction between the values of A and B or anisotropy, and it disregards which is at the head or tail of the spatial vector (Rossi and others, 1992). Furthermore, cross-variograms are affected by small-scale local differences in cell mean and variance (Real and McElhany, 1996). For those reasons, if possible, the cross-covariogram, $\hat{C}_{A B}(\boldsymbol{h})$, and cross-correlogram, $\hat{\rho}_{A B}(\boldsymbol{h})$, ought to be estimated as well (Rossi and others, 1992). The cross-covariogram can be estimated as (Rossi and others, 1992; adapted from Wackernagel, 1995; Real and McElhany, 1996):

$\hat{C}_{A B}(\boldsymbol{h})=\frac{1}{N(\boldsymbol{h})} \sum_{i=1}^{N(\boldsymbol{h})} \sum_{j=1}^{N(\boldsymbol{h})}\left[z_{A}\left(x_{i}\right)-m_{A-\boldsymbol{h}}\right] \cdot\left[z_{B}\left(x_{j}\right)-m_{B-\boldsymbol{h}}\right]$

where $m_{A-\boldsymbol{h}}$ and $m_{B+\boldsymbol{h}}$ are the means of the values of A and B datasets that correspond to the tail and head of the vectors, respectively.

This specification of the cross-covariogram that is unidirectional and anisotropic acknowledges that set A may not have local means equal to the overall mean of the sample space, and the same holds true for set B (Real and McElhany, 1996). The cross-correlogram can be estimated as (Rossi and others, 1992; Real and McElhany, 1996; Saunders and Tobin, 2000):
Table 3. Tests of differences between correlation coefficients of the 3 differently processed solar loading models, for the Scott-Klamath River confluence, August 26, 2010.

[Note: tested with online tool of Fisher r-to-z transformation, http://faculty. vassar.edu/lowry/rdiff.html]

\begin{tabular}{ccc}
\hline Pairs of correlation coefficients & z-value & $\begin{array}{c}\text { Two-tailed } \\
\text { p-value }\end{array}$ \\
\hline (a) and (b) & -0.27 & 0.7872 \\
(a) and (c) & -0.29 & 0.7718 \\
(1) and (2) & -0.38 & 0.7039 \\
(2) and (3) & -0.34 & 0.7339 \\
\hline
\end{tabular}

$$
\hat{\rho}(\boldsymbol{h})=\frac{\hat{C}_{A B}(\boldsymbol{h})}{S_{A-\boldsymbol{h}} S_{B+\boldsymbol{h}}}
$$

where $S_{A-h}$ and $S_{B+h}$ are the standard deviations of the tail value of $A$ vector and the head value of $B$ vector, respectively.

\section{Application and Results}

Although diffuse and direct insolation can be calculated separately, global radiation (without reflected insolation) was the output of interest as it related to the total thermal load to the river.

The output of Solar Model 1, which used the input that both averaged the maximum heights of the VCS and CBEM as well as overshot the resampling target by going to a resolution of $0.3 \mathrm{~m}$ before changing to $3 \mathrm{~m}$, is shown in figure 8 . Note the striping artifacts that resulted from the multiscaled surface being stair stepped due to the resampling procedure.

The output of Solar Model 3, which used the input that maintained the maximum heights of the VCS and CBEM, as well as included less resampling steps, is shown in figure 9. As compared to data shown in figure 8, note both the reduction in striping as well as the increase in detail in the loading patterns (for example, segments of yellow in and around the confluence, sharper representation of the canopy structure).

A scatter plot of the three solar model outputs against the TIR is shown in figure 11.

Quantile-quantile plots are shown in figure 12. The four surfaces were found to have an S-shape and thus fail the test of normal distribution. Results of the two correlation tests, correlation coefficients (tau for Kendall's and rho for Spearman's), and level of significance for each solar model as compared to the TIR are listed in table 2. Across the solar models, Kendall's rank tests give lower correlation coefficients than Spearman's rank tests. For both tests, the data in table 2 suggest that Solar Models 2 and 3 are better correlated with the TIR data than Solar Model 1. Statistically testing the significance of those differences was done with the Fisher r-to-z transformation, which assumes the data are normally distributed and consequently reduces the power of the test in this case (table 3). 
Results of the cross-covariograms for the full extent of the TIR data for Solar Models 2 and 3 are presented in figures 13 and 14. Due to the findings of the Kendall's and Spearman's rank tests, Solar 1 was disregarded in these analyses and effort was made to discern any major differences between Solar 2 and 3. Comparing standardized root-mean-square prediction errors of the two cokriging models suggests that the TIRSolar Model $2(0.6513$, fig. $13 A)$ result is less robust than the TIR-Solar Model 3 (0.7256, fig. $14 A)$ result. The distance at which the TIR is cross-correlated with the solar models, or the major range, is just over $94 \mathrm{~m}$ for Solar Model 2 (fig. $13 B-D$ ) and just over $88 \mathrm{~m}$ for Solar Model 3 (fig. $14 B-D$ ). The direction of the major range's anisotropy between the two models is comparable (336.3 degrees versus 327.1 degrees). Including search direction shows the difference in local means in comparison to the overall sample space and the vectors between datasets in that for Solar Models 2 and 3, they exhibit negative correlation with TIR when searching at 76 degrees (fig. $13 C$ and fig. $14 C$, respectively) and positive correlation when searching at 236 degrees (figs. 13D and 14D, respectively).

Results of the cross-correlation for the full extent of the TIR data are shown in figure 15 . Note that the results have been normalized, and the y-axis represents correlation coefficients between the three pairs of data (Solar Model X against TIR) at various lag distances. The cross-correlations are specified according to equations 9 and 10; however, anisotropy was not included due to software and programming limitations. The plot indicates that for every solar model, the smaller the lag distance, the better the models are correlated with the TIR data. Furthermore, it shows minor and negligible difference in correlation between the three Solar Models and the TIR data, where skewness for all three Solar Model cross-correlations was less than 0.003 (although all three distributions have kurtosis greater than -1.3) and the Pearson's tests for correlation were greater than 0.99 .

\section{Discussion}

In terms of the three outputs, Solar Model 1 (fig. 8) is hypothesized to be less accurate and less correlated with TIR than Solar Models 2 and 3 (fig. 9). In minor support of this, table 2 suggests a statistically significant, positive correlation between the three solar models and the TIR in the extent of the analysis around the Scott River confluence, with Solar Models 2 and 3 having $\sim 0.02$ higher correlation coefficients than Solar Model 1. Even though the statistical test of the Fisher r-to-z transformation assumes normally distributed data and, therefore, it is not a robust measure (Zimmerman and others, 2003), the difference between these correlation coefficients does not appear to be statistically valid (table 3 ). What is surprising is the two tests do not provide conclusive evidence that Solar Model 3 is better than Solar Model 2, nor is Solar Model 1 dramatically different than Solar Models 2 and 3. Overall, the lack of a large, statistically significant difference may suggest that the differences in the processing routines of the three Solar Models have minor influence on their results. Therefore, with nonspatial tests of correlation, it can be concluded that all the models are fairly equal in representing the variability of the TIR data.

It is interesting to note the two nonparametric correlation tests have slightly different interpretations due to differences in their underlying logic and computational formulae-Kendall's represents a probability of the same rank order between two datasets where as Spearman's values the proportion of variability. It is suggested that with large sample sizes, Kendall's tau will be about two-thirds of Spearman's rho (Fredricks and Nelsen, 2007), which is found to be the case here.

Examining the results of the geostatistical tests provides additional insight and inferences to the structure of the data and relationships between the Solar Models. Figures 13 and 14 show the cross-covariogram, $\hat{C}_{A B}(\boldsymbol{h})$, and covariance results of the TIR against Solar Models 2 and 3, respectively. Through exploratory data analyses and semivariogram analysis of individual datasets, it was found that the TIR data and Solar Models 2 and 3 outputs had both north-south and east-west global trends with the Solar Models' trends being even stronger than the TIR. The TIR exhibited directional anisotropy as well. The east-west global trends are to be expected as the river's predominant orientation is east-west. For these reasons, the cross-covariogram analysis included global polynomial interpolation for the Solar Models and directional, anisotropic assessments in the universal cokriging prediction tests. As expected, the universal cokriging results performed better than the ordinary cokriging results as they typically had better rootmean-square standardized results.

The results of the cross-covariograms merit additional discussion. The results of the standardized root-mean-square prediction errors, ideally, ought to be close to one. The lower value of the cokriging models suggests that they are overpredicting the variation of the Solar Models. The results of the search direction demonstrate the asymmetry of the crosscovariograms that would not be present in a single dataset's semivariogram. Controlling for directional anisotropy, the lag distance of the range suggests that the values of the TIR and the solar models can be correlated to somewhere between 88 and $94 \mathrm{~m}$, after which the statistical relationship tapers off. This distance-related nuance between the two models detected by geostatistical analysis is a distinction that the results of the nonparametric correlation tests could not provide. As such, given that the TIR data is considered ground-truth, then this suggests that the solar models have a distance-lagged relationship of nearly 100 meters. A distinction between Solar Models 2 and 3 is a slight difference in the direction of the anisotropy, namely 336 degrees and 327 degrees, respectively. The majority of the results in figures 13 and 14 do not indicate significant differences in the spatial structure between Solar Models 2 and 3; however, the standardized root-mean-square of Solar Model 3 is higher (0.074) and is, therefore, a better predictor of TIR. 

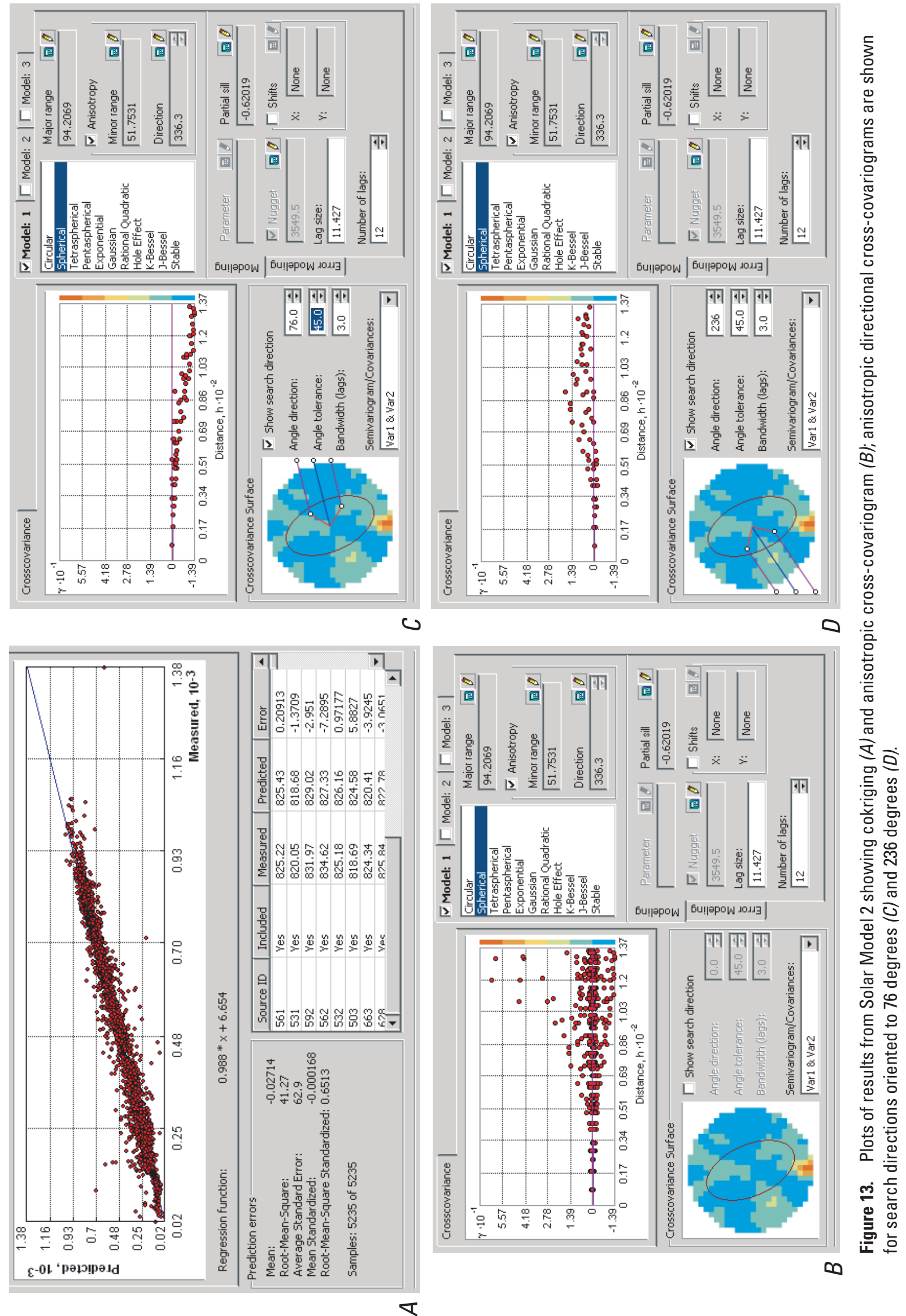

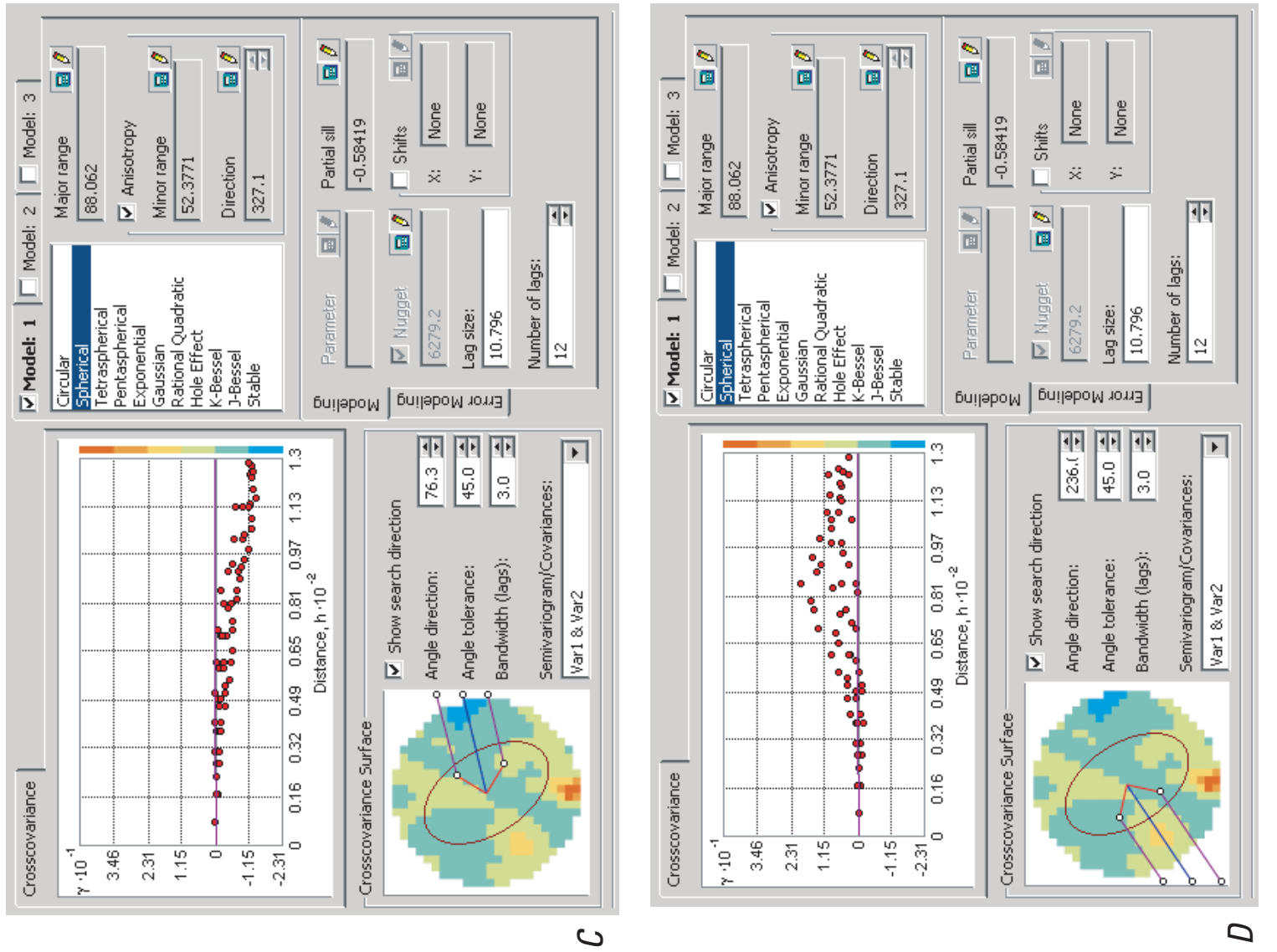

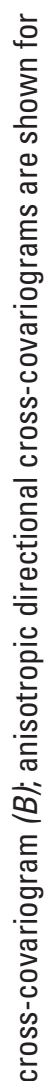
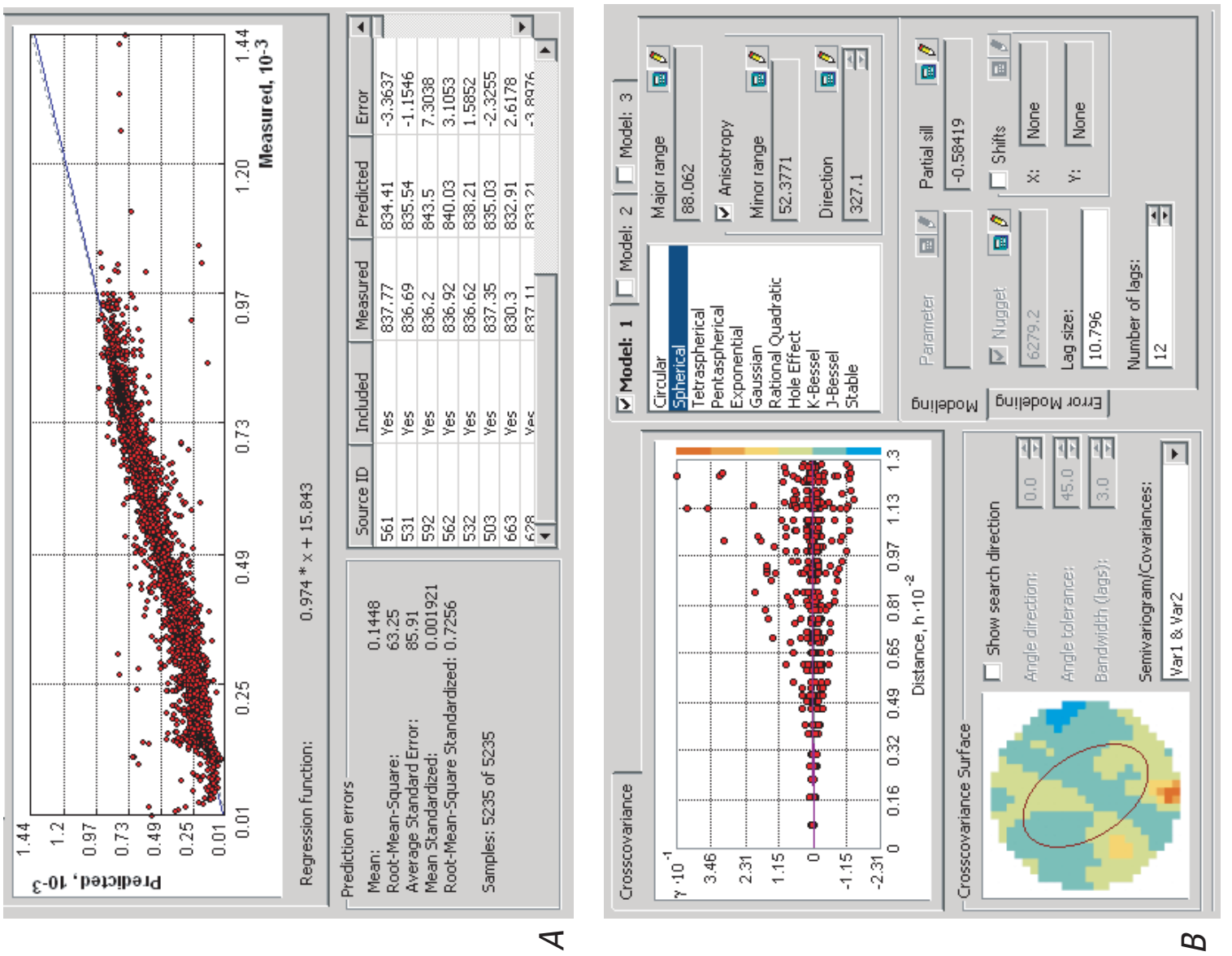

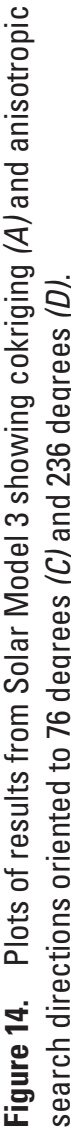


The cross-correlogram, $\hat{\rho}_{A B}(\boldsymbol{h})$, and correlation coefficients at lagged distances (fig. 15) provide validation in terms of the findings of the nonparametric correlation, support for the inference that three models are not significantly different from each other, and intuitive results in terms of their spatial dependence. In terms of the first-and counter to the cross-covariograms that accounted directional anisotropy-none of the solar models were found to outperform the others in terms of their correlation coefficients to the TIR across all lag distances. This suggests the importance of accounting for directional anisotropy in the analysis of the spatial structure of the data, which is supported by the findings of ranges and directionality in the cross-covariograms as discussed above. Without directional anisotropy, as expected, the greater the lag distance, the lower the correlation between any particular solar model and the TIR data.

Aside from the details of the statistical analyses, it is encouraging to see evidence that the solar models developed for this paper are correlated to TIR data. A variety of factors could have made this impossible. First, the solar loading model is a cumulative measure of radiance over time, while the TIR is an instantaneous snapshot of the surface of the river, the temperature of which is subject to hysteresis at a given location and a given time as well. As outlined in equation 2 , the temporal and spatial dynamics further complicate the situation in that hydrologic processes constantly alter the thermal dynamics of the river. This required the usage of geostatistical analyses that address autocorrelation, nonstationarity, and anisotropy.

Having shown the potential and limitations of the solar loading model and methods and the degree to which TIR validated the model's output, it is evident that the technique has utility for understanding, characterizing, and modeling an essential factor in the dynamics of water temperature and the availability of cold water refugia for salmonids in the Klamath River basin. Locations where riparian vegetation and fluvial and watershed morphology interact to provide shade to the water's surface are likely to maintain lower water temperatures in the water column, and downstream of those particular locations as a water packet continues to work its way through the system. This creates an argument for considering the maintenance of riparian vegetation and (or) the restoration of disturbed riparian vegetation and channel morphology. The results of this work incorporate the theoretical considerations laid out in the literature, and they provide an improved method for modeling spatially explicit, anisotropic, upward-looking geometric solar radiation as an essential ecological process to the thermal dynamics of the riverine system. This work can assess the benefits of riparian and channel restoration, estimate the solar loading reductions from different landscape components, and model alternate configurations of biogeomorphic, fluvial systems.
Given involvement by other USGS River and Ecosystems Models and Science initiative (REMS) team members and availability of proposed datasets, extensions of the model could be made into a fuller representation of the temperature dynamics of the system. In particular, the inclusion of other variables associated with equation 2 would improve predictions of temperature dynamics as water moves through the system. For example, the solar loading models did not predict the warmer water measured by the TIR in the lower reaches of the study site (fig. 10, point A) that could be caused by a change in local water depth or streamflow. In some manner, other members of the REMS team are addressing the variables $Q, T_{g w}, T_{w}$, $v, D$, and others through the integration of stream-gage measurements, collection of measurements of temperature in the water column, 1-dimensional, 2-dimensional, and 3-dimensional hydrodynamic models, and bathymetric surface, land surface, water depth, and vegetation canopy measurements by the interpretation of Experimental Advanced Airborne Research LiDAR (EAARL) data that were obtained in spring 2009. Furthermore, the habitat quality, usage, and connectivity within and between cold water refugia by particular fish is being studied through the usage of passive integrated transponder tags and arrays that count their passage by a particular location. Even if these studies do not come to fruition from the efforts of the REMS team, they are important to consider for potential future studies to more comprehensively represent fluvial thermal dynamics and cold water refugia.

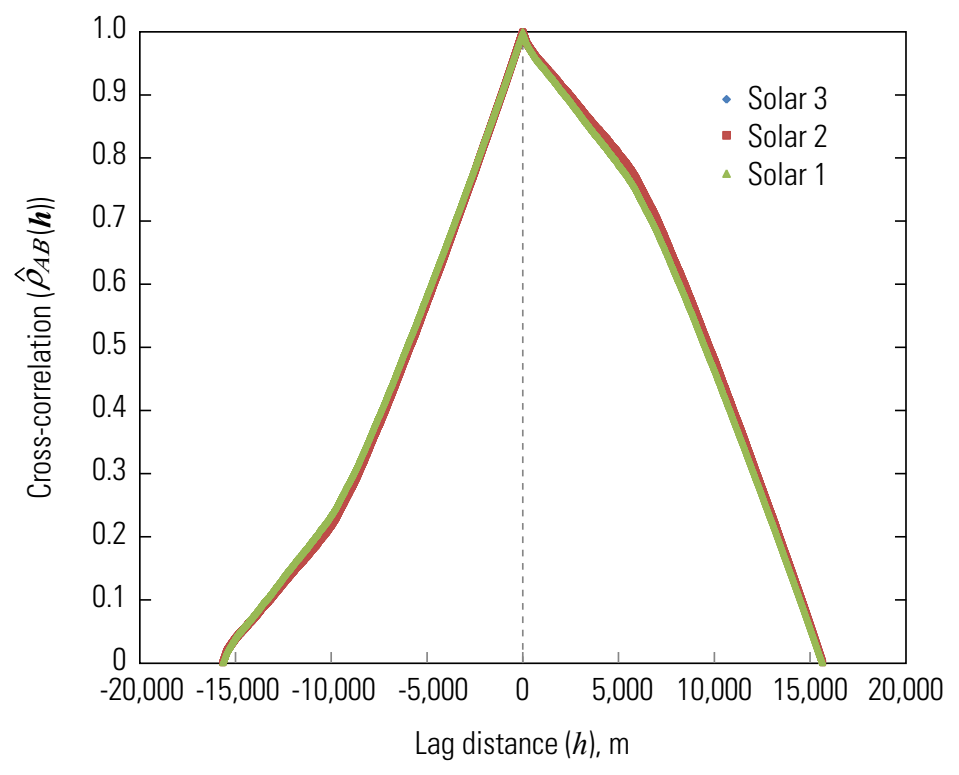

Figure 15. Plot showing cross-correlograms of thermal imagery related to the three differently processed solar models for the Scott-Klamath River confluence on August 26, 2010. 


\section{Future Research}

The authors consider in this section a brief list of potential avenues for future research. They include:

-Segment the extent of the solar models and TIR data at the confluence of the Scott River (for example, approximately easting $497 \mathrm{~km}$, fig. 10), and run the same nonparametric and geostatistical tests to assess potential changes to the statistical relationships and structure of the data by distinguishing the reaches above and below the confluence.

-Sensitivity analysis by altering the sky path, light transmission and diffusion parameters, and isolating the shading contributions from vegetation as opposed to channels and (or) watersheds.

- Repeat TIR flights would allow modeling and analysis of seasonality impacts.

- For additional ground truthing, develop a stratified random sampling design to ensure the full range of shade conditions are represented. Ground truth with pyranometers, radiometers and (or) other shade analysis tools.

- For thermally loaded reaches, conduct classification and regression-tree analysis with ancillary data to determine an environmental envelope, then find other locations on the reach that have similar attributes and simulate vegetation patches to determine the possible load reduction from restoration. Patch location could be done with less statistically robust methods as well.

- For simulation of vegetation growth over time, consider universal increase in vegetation height and varied growth rates given VDDT (for example, willows grow faster than oaks).

-Expand model application and testing to a larger stretch of the Klamath River, continuing to focus on confluences such as Seiad, Independence, and Indian Creeks. These confluences will have different morphological and hydrotemperature characteristics.

- Using exising TIR flights for another confluence and the most robust model from the Scott River confluence, spatial patterns could be predicted at the new confluence and compared to estimates of a new solar loading model to further validate results.

- Consider application in other locations of the country or the world, especially those that are listed by the United States Environmental Protection Agency under the Clean Water Act as temperature impaired. Although only about 26 percent of the waters have been assessed, this represents over 46,000 miles of rivers in the United States (http://iaspub.epa.gov/waters10/attains_nation_cy.control, accessed Dec. 18, 2012).

\section{Acknowledgments}

The authors would like to acknowledge the REMS team for their discussion, insights and contributions to this research, especially Stewart Rounds, Lorraine and Alan Flint, Jennifer Curtis, and Deborah Curry. We would like to recognize the commitment of the USGS and Anne Kinsinger (Associate Director for Ecosystems) to providing long-term funding of this project and research initiative as well as the support of Johathan Smith of the Geographic Analysis and Monitoring Program, and Tracy Fuentes of the northwest area office. Patrick Wright of the Bureau of Reclamation was essential to the success of this project, as he provided the LiDAR bare earth model and raw LAS files. The interaction with and prior efforts of Michael Deas from Watercourse Engineering, Inc. was especially helpful in developing this line of research. Finally, the peer reviews of Stewart Rounds and Gary Barton (both USGS) were very useful and insightful for the improvement of this manuscript.

\section{References Cited}

Abbott, A., 2002, Effect of riparian vegetation on stream temperature in the Shasta River: Davis, Calif., University of California, M.S. thesis, $144 \mathrm{p}$.

Allen, D., Dietrich, W., Baker, P., Ligon, F., and Orr, B., 2007, Development of a mechanistically based, basin-scale stream temperature model-Applications to cumulative effects modeling, presented at the Redwood Science SymposiumWhat does the future hold?, Rohnert Park, Calif.: U.S. Department of Agriculture, Forest Service General Technical Report, PSW-GTR-194, p. 11-24.

Bartholow, J.M., 2000, Estimating cumulative effects of clearcutting on stream temperatures: Rivers, v. 7, no. 4, p. 284-297.

Barton, D.R., Taylor, W.D., and Biette, R.M., 1985, Dimensions of riparian buffer strips required to maintain trout habitat in southern Ontario streams: North American Journal of Fishery Management, v. 5, p. 364-378.

Belchik, M.R., 2003, Use of thermal refugial areas on the Klamath River by juvenile salmonids-Summer 1998: Yurok Tribal Fisheries Program Technical Report, 36 p.

Beschta, R.L., 1997, Riparian shade and stream temperature-An alternative perspective: Ranglelands, v. 19, no. 2, p. 25-28.

Beschta, R.L., Bilby, R.E., Brown, G.W., Holtby, L.B., and Hofstra, T.D.,1987, Steam temperature and aquatic habitatFisheries and forestry interactions, in Salo, E.O., and Cundy T.W., eds., Streamside management-Forestry and fishery interactions, Contribution 57: Seattle, Wash., University of Washington, College of Forest Resources, p. 191-223. 
Beschta, R.L., and Weatheredd, J., 1984, TEMP-84-A computer model for predicting the stream temperature resulting from management of stream side vegetation: U.S. Forest Service, Fort Collins, Colo., 76 p.

Black, T.A., J.M. Chen, X. Lee, and Sagar, R.M., 1991, Characteristics of shortwave and longwave irradiances under Douglas fir forest stand: Canadian Journal of Forest Research, v. 21, p. 1020-1028.

Bogan, T., Mohseni, O., and Stefan, H.G., 2003, Stream temperature-equilibrium temperature relationship: Water Resources Research, v. 39, no. 1245, 12 p.

Bohle, T.S., 1994, Stream temperatures, riparian vegetation and channel morphology in the Upper Grande Ronde River Watershed, Oregon: Oregon State University, M.S. thesis, $127 \mathrm{p}$.

Boyd, M.S., 1996, Heat Source-Stream temperature prediction: Corvallis, Ore., Oregon State University, M.S. thesis.

Brett, J.R., 1952, Temperature tolerance in young Pacific salmon, genus Oncorhynchus: Journal of the Fisheries Research Board of Canada, v. 9, p. 265-323.

Brett, J.R., 1971, Energetic responses of salmon to temperature-A study of some thermal relations in the physiology and freshwater ecology of sockeye salmon (Onorhynchus nerka): American Zoologist, v. 11, no. 1, p. $99-113$.

Brett, J.R., Clarke W.C., and Shelbourn, J.E., 1982, Experiments on thermal requirements for growth and food conversion efficiency of juvenile Chinook salmon: Canadian Technical Report of Fisheries and Aquatic Sciences, no. 1127: Department of Fisheries and Oceans, Fisheries Research Branch, Nanaimo, British Columbia, Canada, 29 p.

Bristow, K.L., and Campbell, G.S., 1984, On the relationship between incoming solar radiation and daily maximum and minimum temperature: Agricultural and Forest Meteorology, v. 31, no. 2, p. 159-166.

Brown, G.W., 1972, An improved temperature model for small streams: Water Resources Research Institute Report 16: Corvallis, Ore., Oregon State University, 20 p.

Brown, G.W., and Krygier, J.T., 1970, Effects of clearcutting on stream temperature: Water Resources Research, v. 6, no. 4, p. 1133-1139.

California Department of Water Resources (DWR), 2001, Watershed study plan - Water quality and aquatic habitat characterization in the Shasta River: Prepared by G.L. Boles, Northern District, Red Bluff, Calif.
Ciannelli, L., Fauchald, P., Chan, K.S., Agostini, V.N., and Dingsør, G.E., 2008, Spatial fisheries ecology—Recent progress and future prospects: Journal of Marine Systems, v. 71, p. 223-236.

Crawley, M.J., 2007, The R Book: West Sussex, England, Wiley, p. 749-786.

Davies-Colley, R.J., and Rutherford, J.C., 2005, Some approaches for measuring and modeling riparian shade: Ecological Engineering, v. 24, p. 525-530.

Davies-Colley, R.J., and Payne, G.W., 1998, Measuring stream shade: Journal of the North American Benthological Society, v. 17, p. 250-260.

Everson, L.B., 1973, Growth and food consumption of juvenile coho salmon exposed to natural and elevated fluctuating temperatures: Corvallis, Ore., Oregon State University, M.S. thesis, 68 p.

Federer, C.A., 1971, Solar radiation absorption by leafless hardwood forests: Agricultural Meterology, v. 9, p. 3-20.

Flint, L.E., and Flint, A.L., 2008, A basin-scale approach to estimating stream temperatures of tributaries to the Lower Klamath River, California, Technical Reports-Landscape and watershed processes: Journal of Environmental Quality, v. 37, p. $57-68$.

Foroosh, H., Zerubia, J.B., and Berthod, M., 2002, Extension of phase correlation to subpixel registration: IEEE Transactions on Image Processing, v. 11, no. 3, p. 188-200.

Fredricks, G.A., and Nelsen, R.B., 2007, On the relationship between Spearman's rho and Kendall's tau for pairs of continuous random variables: Journal of Statistical Planning and Inference, v. 137, p. 2143-2150.

Fu, P., and Rich, P.M., 2000, The Solar Analyst 1.0 Manual: Helios Environmental Modeling Institute (HEMI), Lawrence, Kan.

Fu, P., and Rich, P.M., 2002, A geometric solar radiation model with applications in agriculture and forestry: Computers and Electronics in Agriculture, v. 37, p. 25-35.

Gilbert, J., Mathieu J., and Fournier, F., 1997, The groundwater-surface water ecotone perspective-The state of the art, in Gilbert, J., Mathieu J., and Fournier, F., eds., Groundwater/surface water ecotones-Biological and hydrological interactions and management options: Cambridge, Cambridge University Press, p. 3-8.

Hanson, C.R., 1991, Acute temperature tolerance of juvenile Chinook salmon from the Mokelumne River, Final Report: Hanson Environmental, Inc., Walnut Creek, Calif., 15 p. 
Harte, J., and Shaw, R., 1995, Shifting dominance within a montane vegetation community-Results of a climatewarming experiment: Science, v. 267, p. 876-880

Hatch, E.C., Fisher, A.T., Revenaugh, J.S., Constantz, J., and Ruehl, C., 2006, Quantifying surface water-ground water interactions using time-series analysis of streambed thermal records - Method development: Water Resources Research, v. 42, no. 10, W10410.

Hewlett, J.D., and Fortson, J.C., 1982, Stream temperature under an inadequate buffer strip in the Southeast Piedmont: Water Resources Bulletin, v. 18, p. 983-988.

Holland, K.T., Holman, R.A., Lippmann, T.C., Stanley, J., and Plant, N., 1997, Practical use of video imagery in nearshore oceanographic field studies: IEEE Journal of Oceanic Engineering, v. 22, no. 1, p. 81-92.

Holtby, L.B., McMahon, T.E., and Scrivener, J.C., 1988, Stream temperatures and interannual variability in the emigration timing of coho salmon (Oncorhynchus kisutch) smolts and fry and chum salmon (O. keta) fry from Carnation Creek, British Columbia: Canadian Journal of Fishery Science, v. 46, p. 1396-1405.

Hopkinson, C., and Chasmer, L.E., 2007, Modelling canopy gap fraction from LiDAR intensity, ISPRS workshop on Laser Scanning 2007 and SilviLaser 2007: Espoo, Finland, 5 p.

Hudak, A.T., Lefsky, M.A., Cohen, W.B., and Berterretche, M., 2002, Integration of Lidar and Landsat ETM+ data for estimating and mapping forest canopy height: Remote Sensing of Environment, v. 82, p. 397-416.

Iverson, R.A., 1972, Effects of elevated temperature on juvenile coho salmon and benthic invertebrates in model stream communities: Corvallis, Ore., Oregon State University, Ph.D. dissertation, 98 p.

Kier Associates, 1998, Midterm evaluation of the Klamath River Basin fisheries restoration program, prepared for the Klamath River Basin Fisheries Task Force: Sausalito and Arcata, Calif., Kier Associates, 303 p.

Lark, R.M., 2003, Two robust estimators of the cross-variogram for multivariate geostatistical analysis of soil properties: European Journal of Soil Science, v. 54, p. 187-201.

Larson, L.L., and Larson, S.L., 1996, Riparian shade and stream temperature-A perspective: Rangelands, v. 18, no. 4, p. 149-152.

Lowney, C.L., 2000, River temperature dynamics in the Sacramento River-Measuring and monitoring: University of California at Davis, Ph.D. dissertation.
Lyons, J., Trimble, S.W., and Paine, L.K., 2000, Grass versus trees-Managing riparian areas to benefit streams of central North America: Journal of the American Water Resources Association, v. 36, no. 4, p. 919-930.

Macdonald, J.S., MacIsaac, E.A., and Herunter, H.E., 2003, The effect of variable-retention riparian buffers on water temperatures in small headwater streams in subboreal forest ecosystems of British Columbia: Canadian Journal of Forest Research, v. 33, p. 1371-1382.

Madej, M., Currens, C., Ozaki, V., Yee, J., and Anderson, D., 2006, Assessing possible thermal rearing restrictions for juvenile coho salmon (Oncorhynchus kisutch) through thermal infrared imaging and in-stream monitoring, Redwood Creek, California: Canadian Journal of Fisheries and Aquatic Sciences, v. 63, no. 6.

Mason, J., 1983, Effects of topographic shading on the energy budget of small lakes: Christchurch, New Zealand, University of Canterbury, M.S. thesis.

McCullough, D.A., 1999, A review and synthesis of effects of alterations to the water temperature regime on freshwater life stages of salmonids, with special reference to Chinook salmon: Prepared for the U.S. Environmental Protection Agency, Columbia River Inter-Tribal Fish Commission, Portland, Ore.

Moore, R.D., Spittlehouse, D.L., and Story, A., 2005, Riparian microclimate and stream temperature response to forest harvesting-A review: Journal of the American Water Resources Association, v. 41, no. 4, p. 813-834.

Muller, Etienne, 1997, Mapping riparian vegetation along rivers-Old concepts and new methods: Aquatic Botany, v. 58, no. 3-4, p. 411-437.

Myrick, C.A., and Cech, J.J., 2004, Temperature effects on juvenile anadromous salmonids in California's central valley_-What don't we know?: Reviews in Fish Biology and Fisheries, v. 14, no. 1, p. 113-123.

National Research Council, 2003, Endangered and threatened fishes in the Klamath River Basin-Causes of decline and strategies for recovery: National Academies Press, Washington, D.C., 358 p.

National Research Council, 2008, Hydrology, ecology, and fishes of the Klamath River Basin: National Academies Press, Washington, D.C., 272 p.

North Coast Regional Water Quality Control Board, 2006, Clean Water Act Section 303(d) List of Water Quality Limited Segments - Klamath River Basin (http://www. swrcb.ca.gov/northcoast/water_issues/programs/tmdls/303d/ index.shtml\#current, accessed Dec. 19, 2012). 
Nugent, P.W., 2008, Wide-angle infrared cloud imaging for cloud cover statistics: Bozeman, Mont., Montana State University, M.S. thesis.

Oregon Department of Environmental Quality, 2008, MolallaPudding subbasin total maximum daily load and water quality management plan (http://www.deq.state.or.us/wq/tmdls/ willamette.htm, accessed Jan, 29, 2013).

Oregon Department of Environmental Quality (DEQ), 2010, TMDL modeling review-DRAFT, (http:/www.deq.state.or.us/ wq/tmdls/docs/tmdlmodelsguide.pdf, accessed Dec. 19, 2012).

Pascual, F., and Zhang, H., 2006, Estimation of linear correlation coefficient of two correlated spatial processes, Sankhyā: Indian Journal of Statistics, v. 68, pt. 2, p. 307-325.

Pluhowski, E.J., 1972, Clear-cutting and its effect on the water temperature of a small stream in Northern Virginia: U.S. Geological Survey Professional Paper 800-C, p. C257-C262.

Polehn, R.A., and Kinsel, W.C., 2000, Transient temperature solution for a river with distributed inflows: Water Resources Research, v. 36, p. 787-791.

Popescu, S.C., Wynne, R.H., and Nelson, R.F., 2003, Measuring individual tree crown diameter with Lidar and assessing its influence on estimating forest volume and biomass: Canadian Journal of Remote Sensing, v. 29, no. 5, p. 564-577.

Real, L.E., and McElhany, P.,1996, Spatial pattern and process in plant-pathogen interactions: Ecology, v. 77, no. 4, p. 1011-1025.

Reifsnyder, W.E., and Lull, H.W., 1965, Radiant energy in relation to forests: U.S. Forest Service Technical Bulletin 1344, Washington, D.C.

Riaño, D., Chuvieco, E., Condés, S., González-Matesanz, J., and Ustin, S.L., 2004, Generation of crown bulk density for Pinus sylvestris L. from Lidar: Remote Sensing and Environment, v. 92, p. 345-352.

Rich, P.M., and Fu, P., 2000, Topoclimatic habitat models, Proceedings of the Fourth International Conference on Integrating GIS and Environmental Modeling.

Rich, P.M., Dubayah, R., Hetrick, W.A., and Saving, S.C., 1994, Using Viewshed models to calculate intercepted solar radiation-Applications in ecology: American Society for Photogrammetry and Remote Sensing Technical Papers, p 524-529.

Rishel, G.B., Lynch, J.A., and Corbett, E.S.,1982, Seasonal temperature changes following forest harvesting: Journal of Environmental Quality, v. 11, no. 1, p. 112-116.
Risley, J.C., Constantz, J.A., Essaid, H.I., and Rounds, S.A., 2010, Effects of upstream dams versus groundwater pumping on stream temperature under varying climate conditions: Water Resources Research, v. 46, no. 6, W06517 (also available at http://dx.doi.org/10.1029/2009WR008587, accessed Dec. 19, 2012).

Rossi, R.E., Mulla, D.J., Journel, A.G., and Franz, E.H.,1992, Geostatistical tools for modeling and interpreting ecological spatial dependence: Ecological Monographs, v. 62, no. 2, p. 277-314.

Rounds, S.A., 2007, Temperature effects of point sources, riparian shading, and dam operations on the Willamette River, Oregon: U.S. Geological Survey Scientific Investigations Report 2007-5185, 34 p.

Rutherford, J.C., Davies-Colley, R.J., Quinn, J.M., Stroud, M.J., and Cooper, A.B., 1999, Stream shade-Towards a restoration strategy: New Zealand Department of Conservation, Wellington, New Zealand, 161 p.

Rutherford, J.C., Blackett, S., Blackett, C., L., Saito, C., and Davies-Colley, R.J., 1997, Predicting the effects of shade on water temperature in small streams: New Zealand Journal of Marine and Freshwater Research, v. 31, p. 707-721.

Saunders, M.C., and Tobin, P.C., 2000, Grape Cane Gallmaker (Coleoptera: Curculionidae) and its impact on cultivated grapes: Journal of Economic Entomology, v. 93, no. 3, p. 795-799.

Scott, J.H., 1999, NEXUS—A system for assessing crown fire hazard: Fire Management Notes, v. 59, no. 2, p. 20-24.

Smith, G.K., Guichard, F., Petrovic, F., and McKindsey, C.W., 2009, Using spatial statistics to infer scales of demographic connectivity between populations of the blue mussel, Mytilus spp.: Journal of Limnology and Oceanography, v. 54, no. 3, p. $970-977$.

Sullivan, K., and Adams, T.A., 1990, An analysis of temperature patterns in stream environments based on physical principles and field data: Weyerhaeuser Technical Report, 54 p.

Sutton, R.J., Deas, M.L., Tanaka, S.K., Soto, T., and Corum, R.A., 2007, Salmonid observations at a Klamath River thermal refuge under various hydrological and meteorological conditions: River Research and Applications, v. 23, no. 7, p. 775-785.

Theurer, F.D., Voos, K.A., and Miller, W.J., 1984, Instream water temperature model: U.S. Fish and Wildlife Service Instream Flow Information Paper 16, FWS/OBS-84/15, Fort Collins, Colo., 335 p. 
Thomas, J.W., and the Forest Ecosystem Management Assessment Team, 1993, Forest ecosystem management-An ecological, economic, and social assessment: U.S. Forest Service, Washington, D.C., U.S. Government Printing Office, $141 \mathrm{p}$.

Torgersen, C.E., Faux, R.N., McIntosh, B.A., Poage, N.J., and Norton, D J., 2001, Airborne thermal remote sensing for water temperature assessment in rivers and streams: Remote Sensing of Environment, v. 76, no. 3, p. 386-398.

Vauclin, M., Vieira, S.R., Vachaud, G., and Nielsen, D.R., 1983, The use of cokriging with limited field soil observations: Soil Science Society of America, v. 47, p. 175-184.

Vézina, P.E., and Péch, G.,1964, Solar radiation beneath conifer canopies in relation to crown closure: Forest Science, v. 10 , no. 4, p. 443-451.

Watercourse Engineering, Inc., 2003, Shasta River field monitoring report 2001-2002: Prepared for Shasta Valley Resource Conservations District, Klamath River Basin Fisheries Task Force, United States Fish and Wildlife Service, 53 p.

Wackernagel, H., 1995, Multivariate geostatistics: Berlin, Springer-Verlag, $387 \mathrm{p}$.
Webb, B.W., and Zhang, Y., 1997, Spatial and temporal variability in the components of the river heat budget: Hydrological Processes, v. 11, p. 79-101.

Welles, J.M., and Norman, J.M., 1991, Instrument for indirect measurement of canopy architecture: Journal of Agronomy, v. 83 , no. 5 , p. $818-825$.

Wright, Patrick, 2010, Klamath River dams project—geospatial base map data dictionary 1182: Denver Technical Service Center, Environmental Services Division, MP-180, 12 p. (http://digital.library.ucr.edu/cdri/documents/R145_K_ data_dict_final.pdf, accessed Dec. 1, 2012).

Wurtsbaugh, W.A., and Davis, G.E., 1977, Effects of temperature and ration level on the growth and food conversion efficiency of Salmo garidneri: Journal of Fish Biology, v. 11, no. 2, p. 87-98.

Young, K.A., 2000, Riparian zone management in the Pacific Northwest-Who's cutting what?: Environmental Management, v. 26, p. 131-144.

Zimmerman, D.W., Zumbo, B.D., and Williams, R.H., 2003, Bias in estimatation and hypothesis testing of correlation: Psicológica, v. 24, p. 133-158.
Menlo Park Publishing Service Center, California Manuscript approved for publication February 7, 2013 Edited by Larry B. Slack and Claire M. Landowski Design and layout by Jeanne S. DiLeo 
줄

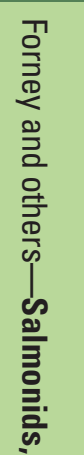

is

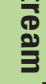

产

商

产

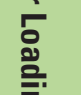

言

음

恋

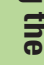

离

ग.․

을

o

$\overline{\bar{\sigma}}$

증

F

혼

क्ञ.

罡

产

备.

. 